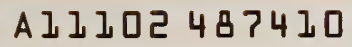

NATL INST OF STANDARDS \& TECH R.I.C.

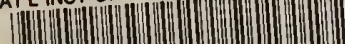

A11102487410

\title{
NBS Ambient Magnetic Field Meter for Measurement and Analysis of Low-Level Power Frequency Magnetic Fields in Air
}

\section{Reference $\quad$ NBS}

P. M. Fulcomer

U.S. DEPARTMENT OF COMMERCE

National Bureau of Standards

Center for Electronics and Electrical Engineering

Electrosystems Division

Gaithersburg, MD 20899

December 1985

Prepared for:

Department of Energy

Office of Electric Energy Systems

$-Q C \quad$ Jendence Avenue, S.W.

100

, DC 20585

.456

86-3330

1985 

"O०

\begin{tabular}{l} 
NBS AMBIENT MAGNETIC FIELD METER FOR \\
MEASUREMENT AND ANALYSIS OF LOW-LEVEL \\
POWER FREQUENCY MAGNETIC FIELDS IN AIR \\
\hline
\end{tabular}

P. M. Fulcomer

U.S. DEPARTMENT OF COMMERCE

National Bureau of Standards

Center for Electronics and Electrical Engineering

Electrosystems Division

Gaithersburg, MD 20899

December 1985

Prepared for:

Department of Energy

Office of Electric Energy Systems

1000 Independence Avenue, S. W.

Washington, DC 20585

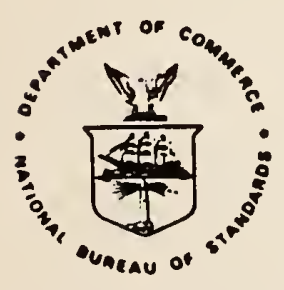

U.S. DEPARTMENT OF COMMERCE, Malcolm Baldrige, Secretary NATIONAL BUREAU Of STANDARDS. Ernest Ambler, Director 

TABLE OF CONTENTS

Page

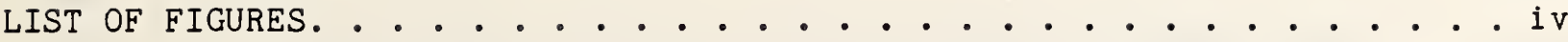

Abstract . . . . . . . . . . . . . . . . . . . . 1

1. INTRODUCTION . . . . . . . . . . . . . . . . . . . 1

2. INSTRUMENTATION. . . . . . . . . . . . . . . . . . . 2

2.1 General Specifications and Design Considerations. . . . . . . . 2

2.2 The Probe . . . . . . . . . . . . . . . . . 4

2.3 The Detector. . . . . . . . . . . . . 8

3. Calibration. . . . . . . . . . . . . . . . . 15

3.1 General Considerations. . . . . . . . . . . . . 15

3.2 Calibration Procedure for the Least Sensitive Ranges. . . . . . 16

3.3 Calibration Procedure for the Most Sensitive Ranges . . . . . 18

3.4 Calibration Uncertainties ................ 22

4. SAMPLE MEASUREMENTS. . . . . . . . . . . . . . . . 30

5. ACKNOWLEDGMENTS. . . . . . . . . . . . . . . . 46

6. REFERENCES . . . . . . . . . . . . . . . . 47 APPENDIX . . . . . . . . . . . . . . . . . . 48 


\section{LIST OF FIGURES}

Page

Figure 1. AMFM-1 frequency response as function of signal amplitude. Frequencies at which clipping occurs (see text) for the various scales are indicated. . . . . . . . . 5

Figure 2. Equivalent circuit of AMFM-1 magnetic field probe. $\mathrm{R}_{\text {in }}$ is the approximate detector input impedance. . . . . . 7

Figure 3. Test set-up for determining the approximate value of the resonant frequency, $\mathrm{f}_{\mathrm{o}}$, of the magnetic field probe . . . . 7

Figure 4. Calculated frequency response for the AMFM-1 magnetic field probe (ratio of probe output voltage to the emf induced by the field vs. frequency of the field) using various values for the detector input resistance, $R_{\text {in }}$. . . 9

Figure 5. Oscilloscope display of the magnetic field waveform superimposed on waveform of the output signal from AMFM-1. Amplitudes of the two waveforms have been made equal for purposes of comparison. . . . . . . . . . . 11

Figure 6. Spectrum analyzer display indicating frequency components of the waveforms shown in figure 5. The traces for the two waveforms are superimposed.............. . 11

Figure 7. AMFM-1 circuit diagram. Approximate amplifier gains are shown beside the range switch positions. The gain of amplifiers $\mathrm{A} 1, \mathrm{~A} 2, \mathrm{~A} 3$, and $\mathrm{A} 5$ is determined by range switch sections $\mathrm{S} 1, \mathrm{~S} 2, \mathrm{~S} 3$, and $\mathrm{S} 4$, respectively. Buffers $A 4$ and $A 6$ have unity gain. Stage $A 7$ is part of the half-wave rectifier supplying output amplitude information to the analog panel meter. This panel meter is used to obtain a peak reading, and also to measure battery voltage when the on, of $\mathrm{switch}$ is in the battery check positions ( $\mathrm{V}+$ or $\mathrm{V}-$ ). The digital panel meter indicates magnetic field strength . . . . . . . . 13

Figure 8. Test set-up and basic procedure for AMFM-1 calibration by voltage injection.

Figure 9. Angles formed between the axis of a solenoid and lines joining a point, $P$, along the axis to the outer edges of the solenoid . . . . . . . . . . 25

Figure 10. Spectrum analyzer vertical scale correction ........ 32 
Figure 11a. Oscilloscope display of laboratory ambient magnetic field waveform. Overhead fluorescent lights on. AMFM-1 indication $=42 \mathrm{nT}$ rms. Vertical scale $=50 \mathrm{nT} / \mathrm{div}$.

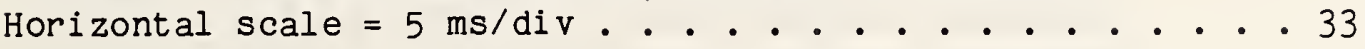

Figure 11b. Absolute scale spectrum analyzer display of figure 11a waveform showing the significant harmonics to be the first, third, and fifth. Vertical scale $=10 \mathrm{nT} / \mathrm{div}$. Horizontal scale $=50 \mathrm{~Hz} / \mathrm{div}$. . . . . . . . . . . 33

Figure 11c. Normalized spectrum analyzer display for the waveform of figure 11a (laboratory ambient field with overhead fluorescent lights on). Percentage of harmonics relative to the fundamental can be determined from this display after applying correction factors from figure 10. Horizontal scale $=50 \mathrm{~Hz} / \mathrm{div}$. . . . . . . . . . . 35

Figure 12a. Oscilloscope display of laboratory ambient magnetic field waveform. Overhead fluorescent lights of $f$. AMFM-1 Indication $=27 \mathrm{nT}$ rms. Vertical scale $=50 \mathrm{nT} / \mathrm{div}$. Horizontal scale $=5 \mathrm{~ms} / \mathrm{div}$. . . . . . . . . . 34

Figure 12b. Absolute scale spectrum analyzer display of figure $12 a$ waveform showing the significant harmonics to be the first, third, fifth, seventh, and ninth, Vertical scale $=10 \mathrm{nT} / \mathrm{div}$. Horizontal scale $=100 \mathrm{~Hz} / \mathrm{div}$. . . . . . . . . . 34

Figure 12c. Normalized spectrum analyzer display for the waveform of figure $12 a$ (laboratory ambient field with overhead fluorescent lights off). Horizontal scale $=100 \mathrm{~Hz} / \mathrm{div}$. . . . . . . 35

Figure 13a. Oscilloscope display of of fice ambient magnetic field waveform. Computer terminal/disc drive on. AMFM-1 Indication $=0.32 \mu \mathrm{T}$ rms. Vertical scale $=0.2 \mu \mathrm{T} / \mathrm{div}$.

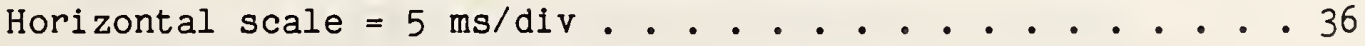

Figure 13b. Absolute scale spectrum analyzer display of figure $13 a$ waveform showing the major harmonics to be the first, third and fifth, with contributions from many others. Vertical scale $=0.1 \mu \mathrm{T} / \mathrm{div}$. Horizontal scale $=100 \mathrm{~Hz} / \mathrm{div} . . . .36$

Figure 13c. Normalized spectrum analyzer display for the waveform of figure 13a (office ambient field with computer terminal/disc drive on). Percentage of harmonics relative to the fundamental can be determined from this display after applying correction factors from figure 10 . Horizontal scale $=100 \mathrm{~Hz} / \mathrm{div}$. . . . . . . . . 38 


\section{LIST OF FIGURES (continued)}

Page

Figure 14a. Oscilloscope display of of fice ambient magnetic field waveform. Computer terminal/disc drive of $f$ AMFM-1 indication $=0.32 \mu \mathrm{T}$ rms. Vertical scale $=0.2 \mu \mathrm{T} / \mathrm{div}$. Horizontal scale $=5 \mathrm{~ms} / \mathrm{div}$. . . . . . . . . . 37

Figure 14b. Absolute scale spectrum analyzer display of figure $14 \mathrm{a}$ waveform showing the significant harmonics to be the first, third, fifth and seventh. Vertical scale $=0.1 \mu \mathrm{T} / \mathrm{div}$. Horizontal scale $=100 \mathrm{~Hz} / \mathrm{div}$............... 37

Figure 14c. Normalized spectrum analyzer display for the waveform of figure 14a (office ambient field with computer terminal/disc drive off). Horizontal scale $=100 \mathrm{~Hz} / \mathrm{div}$. . . . . . 38

Figure 15a. Oscilloscope display of ambient magnetic field waveform obtained in a home, $30 \mathrm{~cm}$ from, and on same level with a section of unloaded $120 \mathrm{~V}$ ac branch circuit wiring located within the wall. AMFM-1 indication $=10 \mathrm{nT}$ rms. Vertical scale $=10 \mathrm{nT} / \mathrm{div}$. Horizontal scale $=5 \mathrm{~ms} / \mathrm{div} . . . . .39$

Figure 15b. Absolute scale spectrum analyzer display of figure 15a waveform showing the significant harmonics to the first, third, fifth, and ninth. Since the amplitude of the first harmonic falls at the top of the verticle scale, this figure can also be used as the normalized spectrum analyzer display. Vertical scale $=1.0 \mathrm{nT} /$ div. Horizontal scale $=100 \mathrm{~Hz} / \mathrm{div} . . . . .39$

Figure 16a. Oscilloscope display of ambient magnetic field waveform obtained in a home, $60 \mathrm{~cm}$ from the front center of an operating 26-inch screen television set. AMFM-1 indication $=0.17 \mu \mathrm{T}$ rms. Vertical scale $=0.2 \mu \mathrm{T} / \mathrm{div}$. Horizontal scale $=5 \mathrm{~ms} / \mathrm{div}$........... 40

Figure 16b. Absolute scale spectrum analyzer display of figure 16a waveform showing a number of significant harmonics which decrease in amplitude from the second through the nineteenth. Vertical scale $=0.2 \mu \mathrm{T} / \mathrm{div}$. Horizontal scale $=200 \mathrm{~Hz} / \mathrm{dlv}$. . . . . 40

Figure 16c. Normalized spectrum analyzer display for the waveform of figure 16a (home ambient field $60 \mathrm{~cm}$ from front of operating 26-inch TV). Percentage of harmonics relative to the fundamental can be determined from this display after applying correction factors from figure 10. Horizontal scale $=200 \mathrm{~Hz} / \mathrm{div}$................ 41 
Figure 17a. Oscilloscope display of ambient magnetic field waveform obtained in a home under the same conditions as figure 16a except that the TV is turned of $f$. AMFM-1 indication $=8.5 \mathrm{nT}$ rms. Vertical scale $=20 \mathrm{nT} / \mathrm{div}$. Horizontal scale $=5 \mathrm{~ms} / \mathrm{div}$. . . . . . . . . . 42

Figure 17b. Absolute scale spectrum analyzer display of figure 17a waveform showing the significant harmonics to be the first and third. Vertical scale $=2.0 \mathrm{nT} / \mathrm{div}$. Horizontal scale $=200 \mathrm{~Hz} / \mathrm{div}$. . . . . . . . . . 42

Figure 18a. Oscilloscope display of ambient magnetic field waveform obtained in a home $15 \mathrm{~cm}$ from the front of an operating microwave oven. AMFM-1 indication $=4.7 \mu \mathrm{T}$ rms. Vertical scale $=5 \mu \mathrm{T} / \mathrm{div}$. Horizontal scale $=5 \mathrm{~ms} / \mathrm{div} . . . . . .43$

Figure 18b. Absolute scale spectrum analyzer display of figure 18a waveform showing the significant harmonics to be the first, third, fourth and fifth. Vertical scale $=1.0 \mu \mathrm{T} / \mathrm{div}$. Horizontal scale $=50 \mathrm{~Hz} / \mathrm{div}$. . . . . . . . . . 43

Figure 18c. Normalized spectrum analyzer display for the waveform of figure $18 \mathrm{a}$ (home ambient field in front of operating microwave oven). Percentage of harmonics relative to the fundamental can be determined from this display after applying correction factors from figure 10 . Horizontal scale $=50 \mathrm{~Hz} / \mathrm{div}$. . . . . . . . . . . 45

Figure 19a. Oscilloscope display of ambient magnetic field waveform obtained in a home under the same conditions as figure $18 \mathrm{a}$ except that the microwave oven is of $\mathrm{f}$. AMFM-1 indication $=52 \mathrm{nT}$ rms. Vertical scale $=50 \mathrm{nT} / \mathrm{div}$. Horizontal scale $=5 \mathrm{~ms} / \mathrm{div}$. . . . . . . . . . . . 44

Figure 19b. Absolute scale spectrum analyzer display of figure 19a waveform showing the significant harmonics to be the first, second, third and fifth. Vertical scale $=10 \mathrm{nT} / \mathrm{div}$. Horizontal scale $=50 \mathrm{~Hz} / \mathrm{div}$. . . . . . . . . . . 44

Figure 19c. Normalized spectrum analyzer display for the waveform of figure 19a (home ambient field in front of non-operating mi crowave oven). Horizontal scale $=50 \mathrm{~Hz} / \mathrm{div} . .$. . . . 45

Figure 20. Configuration of Helmholtz coil pair for generating a magnetic field in the $Z$ direction, together with the coordinate system used in the discussion of field variation at points away from center. . . . . . . . . . 49 

NBS AMBIENT MAGNETIC FIELD METER FOR MEASUREMENT AND ANALYSIS OF LOW-LEVEL POWER FREQUENCY MAGNETIC FIELDS IN AIR

\author{
P. M. Fulcomer
}

Abstract

This report describes a portable, battery-powered magnetic fieldmeter which has been developed to provide improved accuracy in the measurement and analysis of low-level and ambient power-frequency magnetic fields. Accurate measurement of such fields is becoming increasingly important as public concern grows over the possibility that exposure to such fields may produce effects on human health. Included in the report are a description of the instrumentation, a circuit analysis, a discussion of the calibration procedures together with an uncertainty analysis, and some sample measurement results. The instrumentation enables measurement of power-frequency magnetic field in air with an overall uncertainty of less than one percent over a range from 50 nanotesla (500 microgauss) to $200 \mathrm{microtesla} \mathrm{(2} \mathrm{gauss)} \mathrm{and} \mathrm{an} \mathrm{overall}$ uncertainty of less than two percent down to 2 nanotesla (20 microgauss). It also enables the percentage of each harmonic present in the field to be determined to an uncertainty of less than three percent.

Keywords: ambient magnetic field; calibration; calibration uncertainty; flux density; low-level magnetic field; magnetic fieldmeter; magnetic field strength; magnetic flux density; magnetic induction; measure; meter; power frequency magnetic field.

\title{
1. INTRODUCTION
}

The results of some recent epidemiological studies $[1,2,3]$ have generated public concern over the possibility that exposure to power frequency (50-60 Hz) magnetic fields may produce effects on human health, even when the field strength is relatively low, i.e., that which may be present in the home due to nearby transmission lines and/or to electrical wiring and appliances within the home. This has led to biological testing, designed to determine if there is any relationship between magnetic fields and human health. Accurate measurement of low level fields is, of course, necessary both in the biological testing (to assure that the magnetic field level corresponding to specific test results is correctly known), and in determining the field levels to which humans are normally exposed in everyday life. This report describes a portable, battery-powered magnetic fieldmeter which has been developed to provide improved accuracy in the measurement and analysis of such low level ambient magnetic fields.

The instrumentation is described in Part 2, the instrument calibration procedures and an uncertainty analysis are discussed in Part 3, and some sample measurement results are shown in Part 4. 


\section{INSTRUMENTATION}

\subsection{General Specifications and Design Considerations}

The portable, battery-powered instrument developed to measure low-level ambient magnetic fields* has been designated "AMFM-1" for ambient magnetic fieldmeter - version $\|_{1} 1$. It consists of two parts: (1) an electrically shielded magnetic field probe consisting of 2000 turns of wire, wound on a donut-shaped non-inductive core approximately $10 \mathrm{~cm}$ in outside diameter, and (2) a chassis box approximately $7 \mathrm{~cm} \times 20 \mathrm{~cm} \times 25 \mathrm{~cm}$ deep which contains the detector consisting of amplifiers, an integrator, buffers, output indicator and battery power supply. Development time for the present instrument was reduced by using a suitable commercial probe. The probe is connected to the chassis box with a specified length of standard $50-\Omega$ coaxial cable.

The rms value of the output signal is, at present, read with a portable 4-1/2 digit rms multimeter but provision has been made for inclusion of an rms to dc converter within the box and a 4-1/2 digit LCD readout on the front panel. Also included on the front panel is a small analog output display for determining the maximum field at a given location and for checking battery voltage. Two nine-volt batteries power the unit and should enable continuous operation for at least 36 hours.

A portable, low frequency ( $5 \mathrm{~Hz}$ to $50 \mathrm{kHz}$ ), commercial, spectrum analyzer is included as part of the measurement system. Connection of the spectrum analyzer to the AMFM-1 output permits determination of harmonic content in the magnetic field. The percent of each harmonic present can be measured with an uncertainty of less than $\pm 3 \%$ of reading. Harmonics below the 11 th can be measured to this uncertainty even when larger than the fundamental. Higher order harmonics must be less than the fundamental.

Five measurement ranges, in multiples of 10 , are provided by the AMFM-1 from 0.02 microtesla ( 0.2 milligauss) to $200 \mathrm{microtes} l a$ (2 gauss) full scale. Uncertainty of measurements which are above one-tenth scale on the three highest ranges and above one-quarter scale on the fourth highest range is less than $\pm 1 \%$. This includes a measurement range from 50 nanotesla ( 0.5 milligauss) to 200 microtesla ( 2 gauss). Measurements down to 2.0 nanotesla (20 microgauss) can be made with at least 4-digit resolution on the most sensitive range with an uncertainty of less than $\pm 2 \%$. Measurements down to 0.2 nanotesla ( 2 microgauss) are possible with 3 -digit resolution but uncertainty is an order of magnitude greater.

\footnotetext{
*A magnetic fieldmay be described and measured in terms of magnetic flux density, represented by the symbol $B$, or in terms of magnetic field strength, represented by the symbol $\mathrm{H}$. The two are related by the magnetic permeability, $\mu$, of the medium in which the measurement is made $(B-\mu H)$. For air, this permeability is a constant so that either quantity is applicable. The instrument described herein is calibrated in units of magnet1c flux density (tesla).
} 
Frequency response of the instrument is, at present, limited mainly by the probe (pickup coil) and varies less than one db from approximately $20 \mathrm{~Hz}$ to $3 \mathrm{kHz}$, thus allowing complex fields consisting of a $50-$ or $60-\mathrm{Hz}$ fundamental frequency and various percentages of harmonics and subharmonics to be characterized. Between $30 \mathrm{~Hz}$ and $600 \mathrm{~Hz}$ the frequency response is flat to within $0.4 \mathrm{~dB}$ or approximately $5 \%$. The frequency response of the detector alone (not including probe) varies less than $\pm 1 \mathrm{~dB}$ from $10 \mathrm{~Hz}$ to more than $20 \mathrm{kHz}$. The probe frequency response is down $3 \mathrm{~dB}$ at $6 \mathrm{kHz}$ and $6 \mathrm{~dB}(50 \%)$ at $12 \mathrm{kHz}$.

Despite frequency limitations imposed by the present probe, an improvement in probe frequency response would not necessarily lead to an improvement in the overall frequency response of the present instrument. With the exception of Hall effect probes, the signal from commercially available magnetic field probes is proportional to the derivative of the magnetic field. Consequently, the percentage of each harmonic present in the magnetic field is weighted by its harmonic number. One advantage of this phenomenon is that an oscilloscope trace of the amplified signal clearly shows the presence of harmonics. However, a meaningful measurement of magnetic field level cannot be made until the harmonics are returned to their true proportion of the fundamental. This is accomplished by means of an integrator included in the detector. To avoid signal-to-noise and nonlinearity problems in the integrator at very low level inputs, some stages of amplification must precede the integrator. A potential difficulty arises when higher level signals with high harmonic content are applied to this amplifier. The undue weighting and subsequent amplification of the harmonic frequencies can overload a final amplifier stage causing limiting or clipping to occur. Compromises in design must be made to avoid this situation if a higher frequency response is desired.

The use of a Hall-device probe to by-pass the problems described above has, unfortunately, other disadvantages. At present, achieving high sensitivity is a problem when using a probe based on the Hall effect. The use of one was not attempted here because of the need to measure very low level signals. This does not preclude the use of such a probe at a later date however, if probe materials with higher Hall coefficients become available. Use of a Hall probe would require that (1) the integrator stage be replaced by an amplifier, (2) suitable changes be made in the input network and possibly in overall amplifier gain, and (3) the instrument be recalibrated.

When using a field-derivative-type probe (as used by the AMFM-1) a reduced overall output might solve the potential amplifier-overloading problem but at the expense of good low noise performance on the most sensitive range. Other solutions would be to reduce the dynamic range of the instrument or to vary the position of the integrator within the amplifier stages depending on the range selected. None of the above alternatives was used in the AMFM-1, however, because each has an of fsetting disadvantage and because even at full scale output, where the clipping would first occur, the AMFM-1 responds to signals up to $600 \mathrm{~Hz}$ without clipping on all but the highest or least sensitive, $200 \mu \mathrm{T}$, range. This means that in most practical situations (where ambient fields are less than $20 \mu \mathrm{T}$ ) the 10th harmonic of $60 \mathrm{~Hz}$ could be $100 \%$ of the fundamental and still be measured correctly by the AMFM-1. For output signals which are a lower percentage of full scale or for harmonic frequencies which are a lower percentage relative to the fundamental (or both), the 
harmonic frequency that can be measured (no clipping) increases as shown in figure 1. As an example, the harmonic content of a signal whose fundamental amplitude is below $15 \%$ of full scale can be measured to beyond $3 \mathrm{kHz}$, even if the amplitudes of the harmonic components are equal to the fundamental. The same approximate $3-\mathrm{kHz}$ limit applies to harmonic components which are less than approximately $15 \%$ of a full scale fundamental. This performance permits accurate measurement for nearly all practical situations and further complication of the design was not warranted.

On the least sensitive range $(200 \mu \mathrm{T})$, clipping of harmonic components which are $100 \%$ of a full scale fundamental will occur at frequencies above $120 \mathrm{~Hz}$. The clipping initiation point improves to $240 \mathrm{~Hz}$ for signals which are $50 \%$ of a full scale fundamental and to $1.2 \mathrm{kHz}$ for signals which are $10 \%$ of a full scale fundamental. Figure 1 gives a summary of the above results.

A check to determine if clipping is occurring on a given range can be made by switching the detector to the next higher (less sensitive) range. The signal reaching the integrator will now be a smaller percentage of full scale, and less or no clipping will occur. The two readings will be significantly different if clipping is occurring on the more sensitive range. The readings for the two ranges will be about the same if no clipping is occurring.

\subsection{The Probe}

The probe is an inductive type which is widely used in the measurement of alternating current magnetic fields. It consists of 2000 electricallyshielded turns of wire, wound on a donut-shaped noninductive core. According to Faraday's Law, the voltage (emf) induced in the wire loop by a time varylng field is

$$
e m f=-N A(d B / d t)
$$

where $B$ is the component of the magnetic field parallel to the coll axis, $N$ the number of turns in the coll, and $A$ the area enclosed by the coll. The magnetic field is assumed to be uniform over area A. Higher sensitivity can be achieved by making the product NA large, but this must be balanced against either or both ( 1 ) poorer frequency response, as a result of higher inductance (more turns) in the coil, and (2) decreased ability to measure small areas of concentrated magnetic field, since the field measured is the average of that over the area A. As previously noted, the AMFM-1 is intended to measure the general level of ambient power frequency magnetic fields. In this particular case, sensitivity has a higher priority than either high frequency response or the ability to resolve the field measurement over a small area. The mean diameter of the probe is approximately $8.75 \mathrm{~cm}$, and 1 ts response is down approximately $3 \mathrm{~dB}$ at $6 \mathrm{kHz}$.

For sinusoidal magnetic fields, eq (1) may be expressed (neglecting the negative sign) as

$$
\text { emf }=2 \pi f N A B \cos \phi
$$

where $f$ is the frequency, $B$ is the rms value of the magnetic field, and $\phi$ is the angle between the field and the axis of the probe. The cosine term 


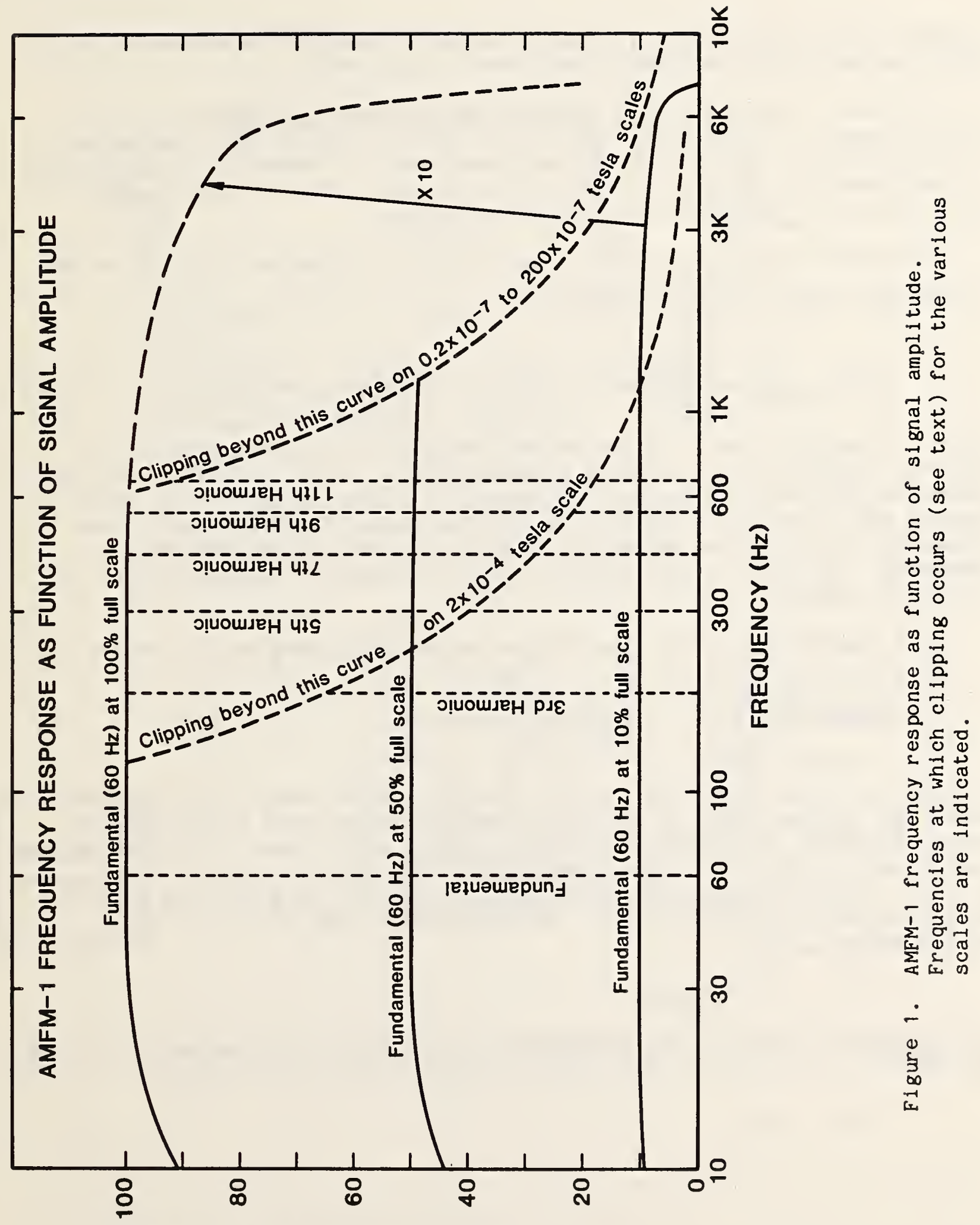

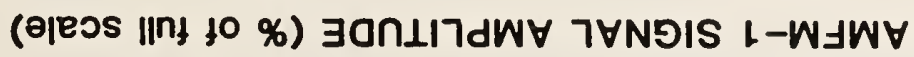


becomes unity if the probe is slowly* rotated to achieve the maximum $B$ value as indicated by the instrument front panel analog meter.

Frequency response of the probe can be calculated from the equivalent circuit shown in figure 2 [4]. The probe and the coaxial cable connecting it to the detector are represented by an inductance $L$ in series with a resistance $r$ plus a parallel distributed capacitance $C$. Emf is the voltage induced in the probe and $R_{\text {in }}$ is located at the detector input.

The probe output, $v_{p_{0}}$ which is applied to the detector input, is related to the emf induced in the probe by [4]

$$
|A|=\frac{{ }_{p_{0}}}{e m f}=\left[\left[\frac{\left(R_{\text {in }}+r\right)}{R_{\text {in }}}-\omega^{2} L C\right]^{2}+\left[\omega\left(\frac{L}{R_{\text {in }}}+C r\right)\right]^{2}\right]^{1 / 2},
$$

where $\omega$ is equal to $2 \pi f$. To reduce the possibility of oscillation in the detector amplifiers, the value of A should remain close to unity and not peak before falling off with increasing frequency. Higher values for $R_{\text {in }}$ cause peaking and a sharp fall-of $f$ in $A$, a possible cause of oscillation. Lower values for $R_{\text {in }}$ allow the value of $A$ to roll of $f$ gently with increasing frequency. Tóo low a value, however, causes unnecessary reduction in the frequency response.

For values of $R_{\text {in }}$ such that $1 / R_{\text {in }} \gg \omega C$ and $R_{\text {in }} \geq \omega L$, eq (3) reduces to

$$
|A|=\left[\frac{\left(R_{\text {in }}+r\right)^{2}}{R_{\text {in }}^{2}}+\left(\frac{\omega L}{R_{\text {in }}}\right)^{2}\right]^{-1 / 2},
$$

because the terms containing the capacitance $C$ can be dropped. It should be noted that because the $C$ of eq (3) includes the distributed capacity of the cable connecting the probe and detector, cable lengths longer than 1 meter may require more analysis. Longer cable lengths will require the use of a dedicated cable. Equation (4) describes the behavior of a low pass RL filter with a cutoff frequency $\omega_{C}=R / L$. For frequencies less than $\omega_{C}, A$ is determined by

$$
|A|=R_{\text {in }} /\left(R_{\text {in }}+r\right) \text {. }
$$

For frequencies above $\omega_{c}$ the attenuation is dominated by the second term of eq (4) and

$$
|A|=\omega_{c} / \omega \text {. }
$$

\footnotetext{
*Slow rotation is required to avoid a false indication that an ac magnet $1 \mathrm{c}$ field is present, when in truth the indication may be caused by rotating the coil through the earth's do magnetic field.
} 


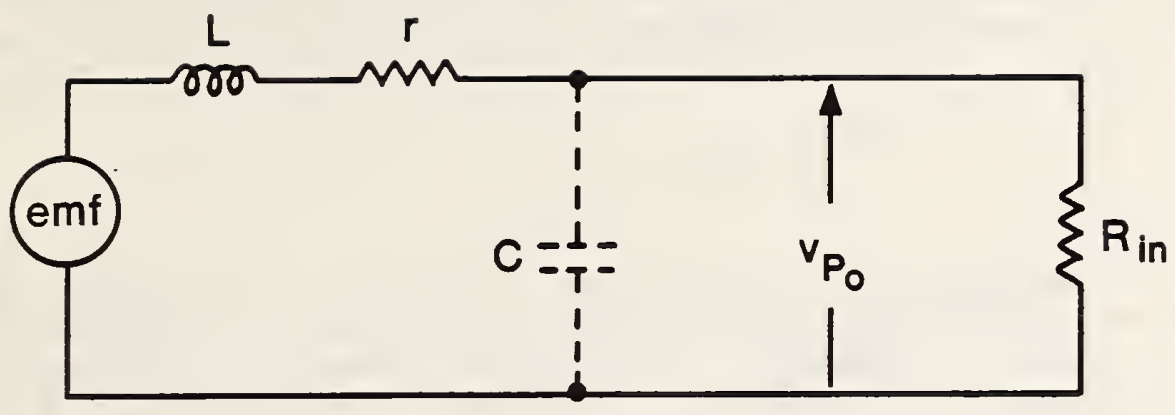

Figure 2. Equivalent circuit of AMFM-1 magnetic field probe. $R_{\text {in }}$ is the approximate detector input impedance.

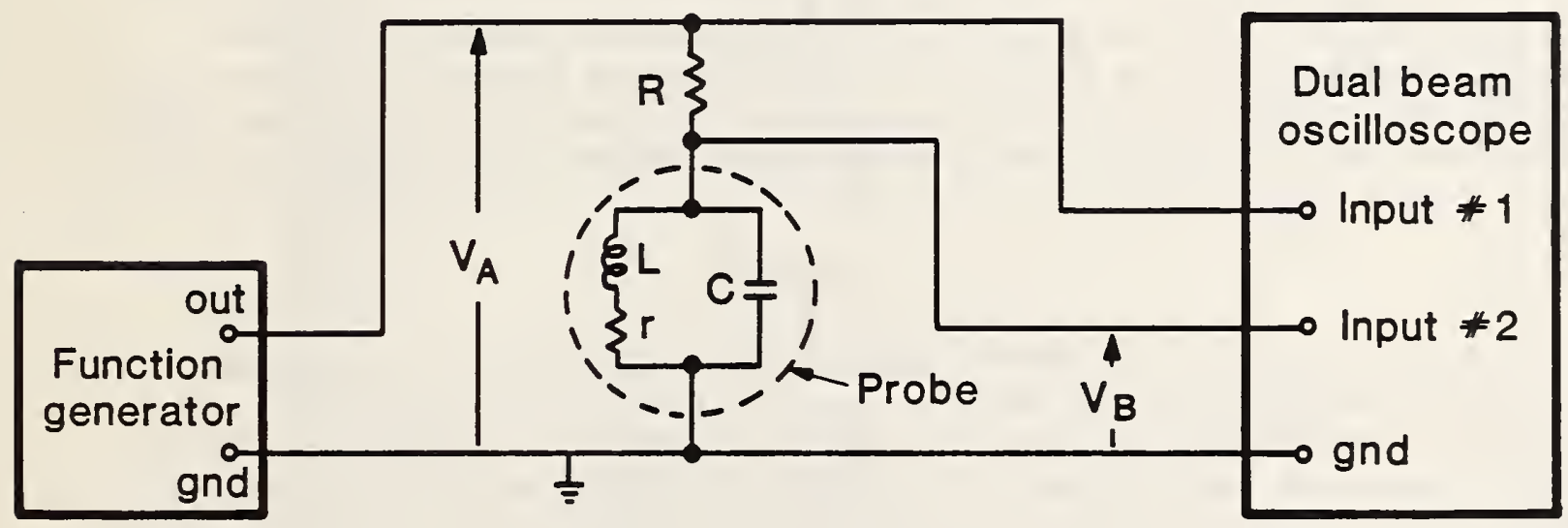

Figure 3. Test set-up for determining the approximate value of the resonant frequency, $f_{0}$, of the magnetic field probe. 
Approximate values for $L$ and $r$ can be obtained with a good quality RLC bridge. An approximate value for $C$ can be calculated by first experimentally determining the resonant frequency, $f_{0}$, of the probe, and then using the relationship below, (frequency of resonance for a parallel LC circuit where $\omega L \gg r$ )

$$
\mathrm{f}_{0}=\frac{1}{2 \pi}\left[\frac{1}{\mathrm{LC}}\right]^{1 / 2}
$$

to solve for $C$ by substituting for the values of $\mathrm{f}$ and $\mathrm{L}$. The approximate value for $f$ can be determined experimentally by means of the relatively simple test ${ }^{\circ}$ set-up shown in figure 3 . The function generator frequency should be increased while keeping its output, $V_{A}$, constant. The frequency at which the voltage across the probe, $V_{B}$, peaks ${ }^{A}$ 's the approximate resonant frequency. Input impedance of the vertical ${ }^{\prime}$ oscilloscope amplifier used to measure $V_{B}$ should be at least $1 \mathrm{M} \Omega$. Probe coil resistance, $r$, reduces the peak value of

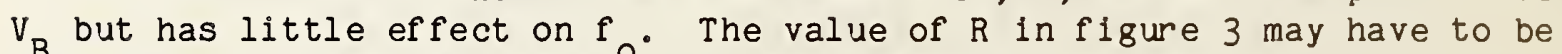
changed to achieve best sensilivity for observing the peak value of $V_{B}$.

Methods for rigorous determination of the probe coil parameters $r$, $L$, and $C$ [4] of figure 2 are not specified nor needed here. Approximate values enable determination of a suitable value for $R_{\text {in }}$ to maximize the probe frequency response. The approximate values for $\mathrm{L}, \mathrm{r}$, and $\mathrm{C}$ of the plckup coil used for the AMFM-1 are shown in figure 4 along with curves showing the variation in $\mathrm{V}_{\mathrm{p}}$ / emf with frequency as calculated from eq (3), for various values of $R_{i n}$. The best value for $R_{i n}$ is that which results in a probe frequency résponse which is flat to roll-of $f$, such as that which a value $R$ in between $27 \mathrm{k} \Omega$ and $30 \mathrm{k} \Omega$ provides* (see figure 4). Calibration of the field meter at various frequencies then provides the complete instrument frequency response (see figure 1).

\subsection{The Detector}

The detector portion of AMFM-1 amplifies and integrates the voltage induced into the probe by the ambient magnetic field, resulting in an ac voltage whose waveshape and harmonic content (within the frequency range of the AMFM-1) matches that of the ac currents which produced the ambient magnetic field. This ac voltage is measured by a 4-1/2 digit true rms meter to indicate the magnitude of the magnetic field present, and is also avallable at two front and one rear panel output connectors for observation by an oscilloscope or for spectrum analysis to determine the number and percentage of harmonics present.

*Termination of the probe with a relatively low value resistance results in a very small circulating current due to the back emf induced in the coll by the magnetic field which is being measured. The field produced by this ciurent is, at the center of the coil, approximately $0.38 \%$ of the fleld being measured and very nearly in phase quadrature with 1t. The effect is taken into account, however, when the probe and detector are callbrated as one unit. The phase shift introduced is negligible, i.e., less than 0.22 degrees. 


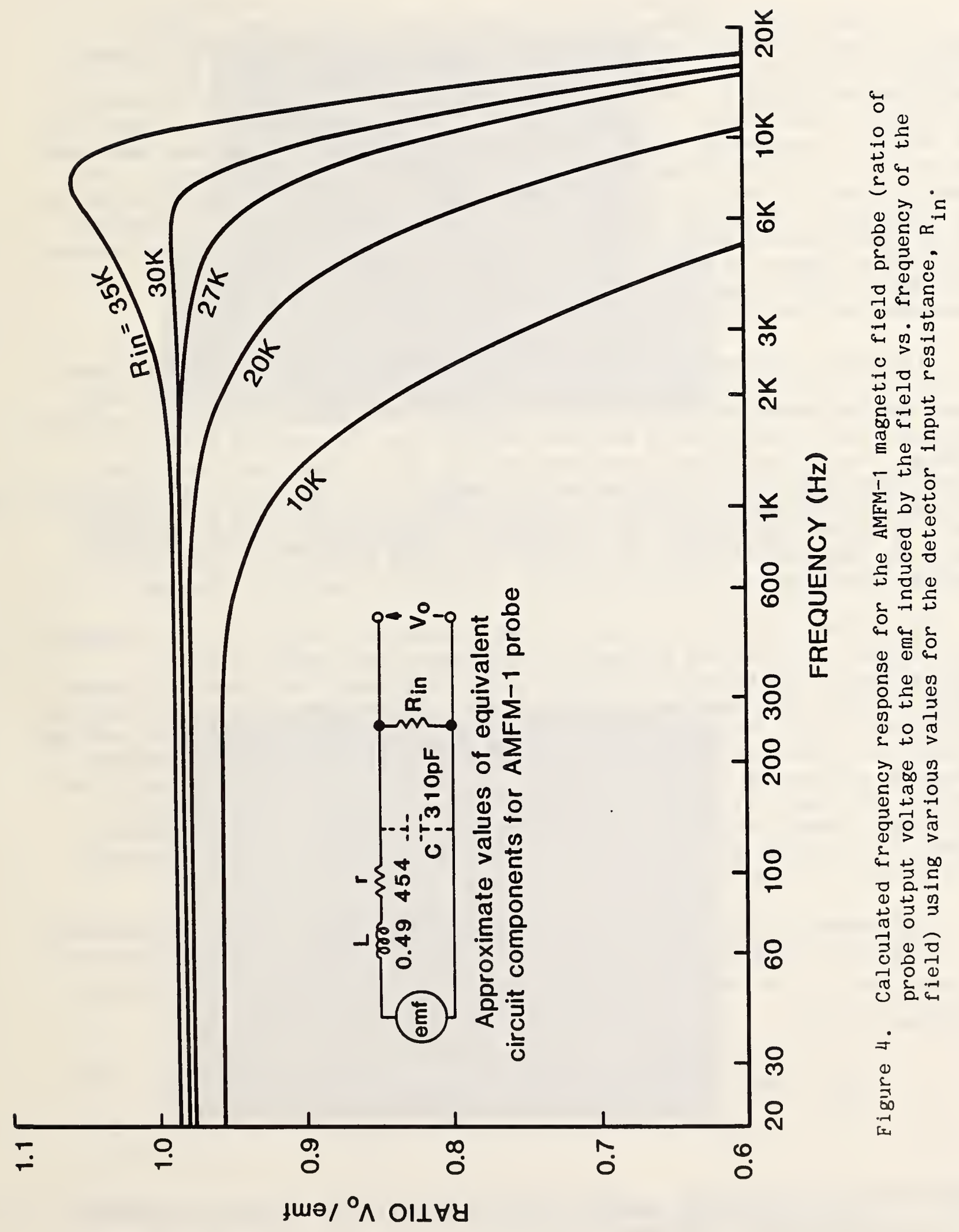


To confirm AMFM-1 operation, the probe was placed within a set of Helmholtz coils and the current* to the coils was supplied by a programmable waveform generator/power amplifier combination. Figure 5 shows an oscilloscope display of the current waveform superimposed on the waveform of the AMFM-1 output signal. The amplitudes of the two waveforms have been made the same for purposes of comparison. The current waveform contains about $40 \%$ 3rd harmonic, 19\% 5th harmonic, 8.5\% 7 th harmonic and $4 \% 9$ th harmonic. The phases of the 3 rd and 5 th harmonics have been shifted $+90^{\circ}$ relative to the 60 Hz fundamental. Figure 6 is the superimposed spectrum analyzer display for the two waveforms shown in figure 5. No differences between the superimposed displays of figures 5 and 6 are discernable, indicating that for the frequencies shown, the probe and detector of the AMFM-1 adequately characterized the spectral composition.

In addition to amplifiers and an integrator, the detector also includes (1) the 4-1/2 digit LCD front panel readout and accompanying true-rms-to-dc converter necessary to drive it, (2) a small, front panel, dc current, analog meter for use in determining maximum reading** and in checking battery voltage, plus a simple half wave rectifier to drive the meter from the ac output when used for determining maximum reading, (3) an on-of f battery check switch, (4) a range switch, and (5) the battery power supply. At present, item (1) above, has not yet been physically incorporated into the detector box. The detector ac output is instead indicated on the $2.0 \mathrm{~V} \mathrm{rms} \mathrm{scale} \mathrm{of} \mathrm{a}$ separate portable, battery operated, 4-1/2 digit, true rms multimeter.

The output indication is calibrated in tesla for each of the instrument's Pive ranges. For the two highest or least sensitive ranges (200 and 20 microtesla), calibration is accomplished by placing the probe in a known magnetic field and recording the output meter indication for various values of this known field. Because of the presence of uncontrollable low level amblent fields, the lowest or most sensitive ranges (2.0, 0.2 and $0.02 \mathrm{microtesla}$ ) cannot be calibrated by this method. A "voltage injection" technique is used instead. Voltage injection is also used for portions of the 200 and 20 microtesla ranges for comparison with the direct method (where the probe is inserted in a known magnetic field). Calibration procedures are explalned more fully in the next section.

The magnetic field probe described in section 2.2 is found experimentally to produce an output voltage, $v_{p}$, of approximately $3.91 \mathrm{mV}$ per microtesla at $60 \mathrm{~Hz}$. This $v_{p_{0}}$ is actually the input voltage for the amplifier and can be expressed as

$$
v_{p_{0}}=v_{\text {in }}=3.91 \frac{\rho}{60} \mathrm{mv} / \mu \mathrm{T}
$$

\footnotetext{
*This current produces the magnetic field within the colls, and 1 ts waveform coincides with that of the magnetic field.
}

**Determination of maximum is difficult when using a digital meter. 


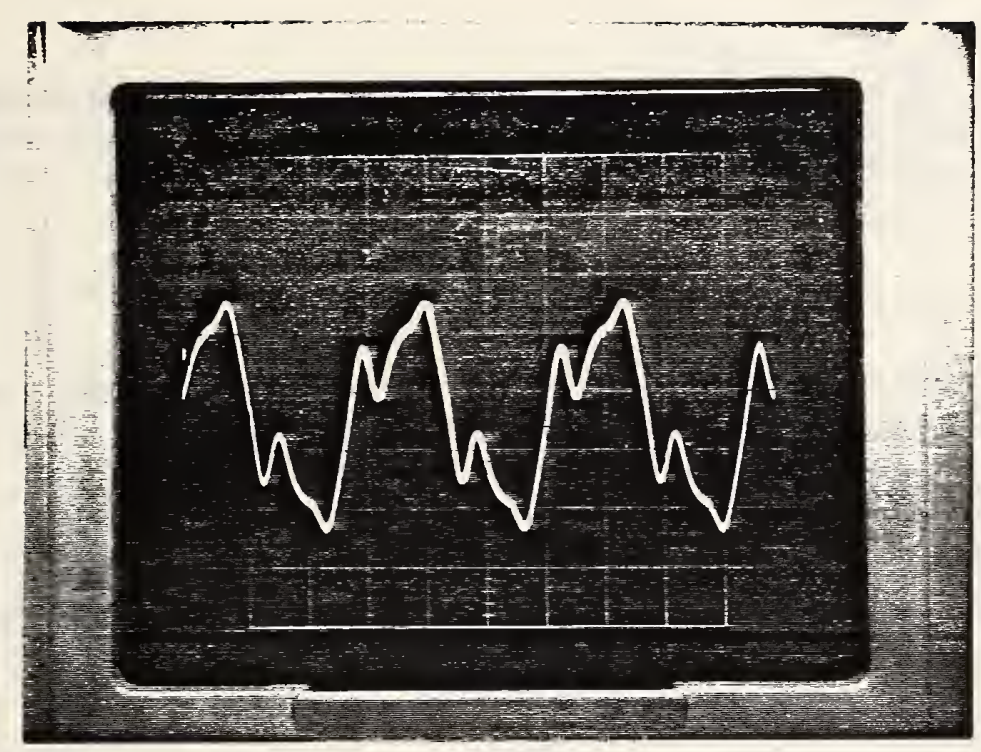

Figure 5. Oscilloscope display of the magnetic field waveform superimposed on waveform of the output signal from AMFM-1. Amplitudes of the two waveforms have been made equal for purposes of comparison.

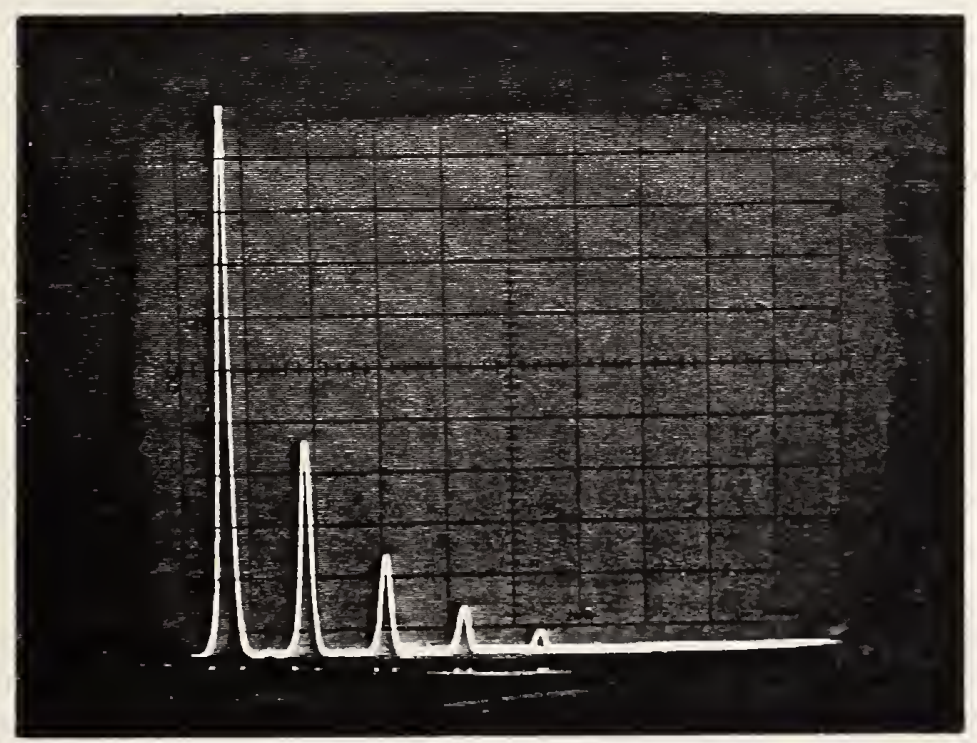

Figure 6. Spectrum analyzer display indicating frequency components of the waveforms shown in figure 5. The traces for the two waveforms are superimposed. 
where $\mathrm{f}$ is the frequency of any harmonic contributing to the total magnetic field, e.8., for the third harmonic $f=180 \mathrm{~Hz}$ and $v_{i n}=11.73$ millivolts/ microtesla. Full scale indication on the digital readout requires $2.0 \mathrm{~V}$ rms at the AMFM-1 output or

$$
v_{0}=2.0 \mathrm{~V} \text { rms, full scale. }
$$

Since the most sensitive range (range E) for the AMFM-1 is $0.02 \mathrm{mlcrotesla}$ full scale, $v_{\text {in }}$ for full scale output at $60 \mathrm{~Hz}$ would be, from eq (8),

$$
v_{\text {in }}=3.91 \frac{60}{60} \frac{\mathrm{mV}}{\mu \mathrm{T}} \times 0.02 \mu \mathrm{T}=78 \mathrm{uV} \text { and }
$$

the amplifier gain, G, required to produce the $2.0 \mathrm{~V}$ rms full scale output meter indication is thus

$$
\mathrm{G}=\frac{\mathrm{v}_{\mathrm{O}}}{\mathrm{v}_{\text {in }}}=\frac{2.0}{78 \mu \mathrm{V}} \mathrm{V}=25,640 .
$$

Amplification required for the four less sensitive ranges (ranges $D$ to $A$ ) are progressive factors of ten less than the above.

At minimum battery voltage, overload or clipping of the amplifier output signal occurs when the signal exceeds approximately 11.5 volts peak-to-peak or $4 \mathrm{~V}$ rms. This is no problem for low harmonic content $60-\mathrm{Hz}$ signals, but as described in section 2.1 , it does become a problem for signals with relatively large amounts of higher order harmonics. Equation (8) indicates that the input signal amplitude (and hence the output signal of a linear amplifier) increases with frequency. Integration counteracts this effect. The amplification or gain of an integrator stage is a function of $1 / \mathrm{f}$.

The AMFM-1 detector consists of an amplifier section with maximum gain of approximately 5128 followed by an operational amplifler integrator with a maximum gain of $5 .^{*}$ The two together produce the required 25,640 gain for full scale indication on the most senstive range. Maximum output from the amplifier section is approximately $0.4 \mathrm{~V} \mathrm{rms}$ at $60 \mathrm{~Hz}$ for ranges $B$ through $E$, and will not increase to the $4 \mathrm{~V}$ rms clipping limit until 100\% of the tenth or higher harmonics are present - an exceedingly unlikely occurrence. See section 2.1 and figure $i$ for further discussion of design considerations in amplifier-integrator placement and of the limit to operation imposed by possible clipping.

Three stages of amplification are used (see circult diagram of figure 7) to provide the high total galn of 5128 needed for the most sensitive range. The maximum gain of an individual stage is 25 . Noninverting operational amplifier stages are used for the high input, low output impedance that they provide.

*The integrator gain is reduced to unity for range $A$. 


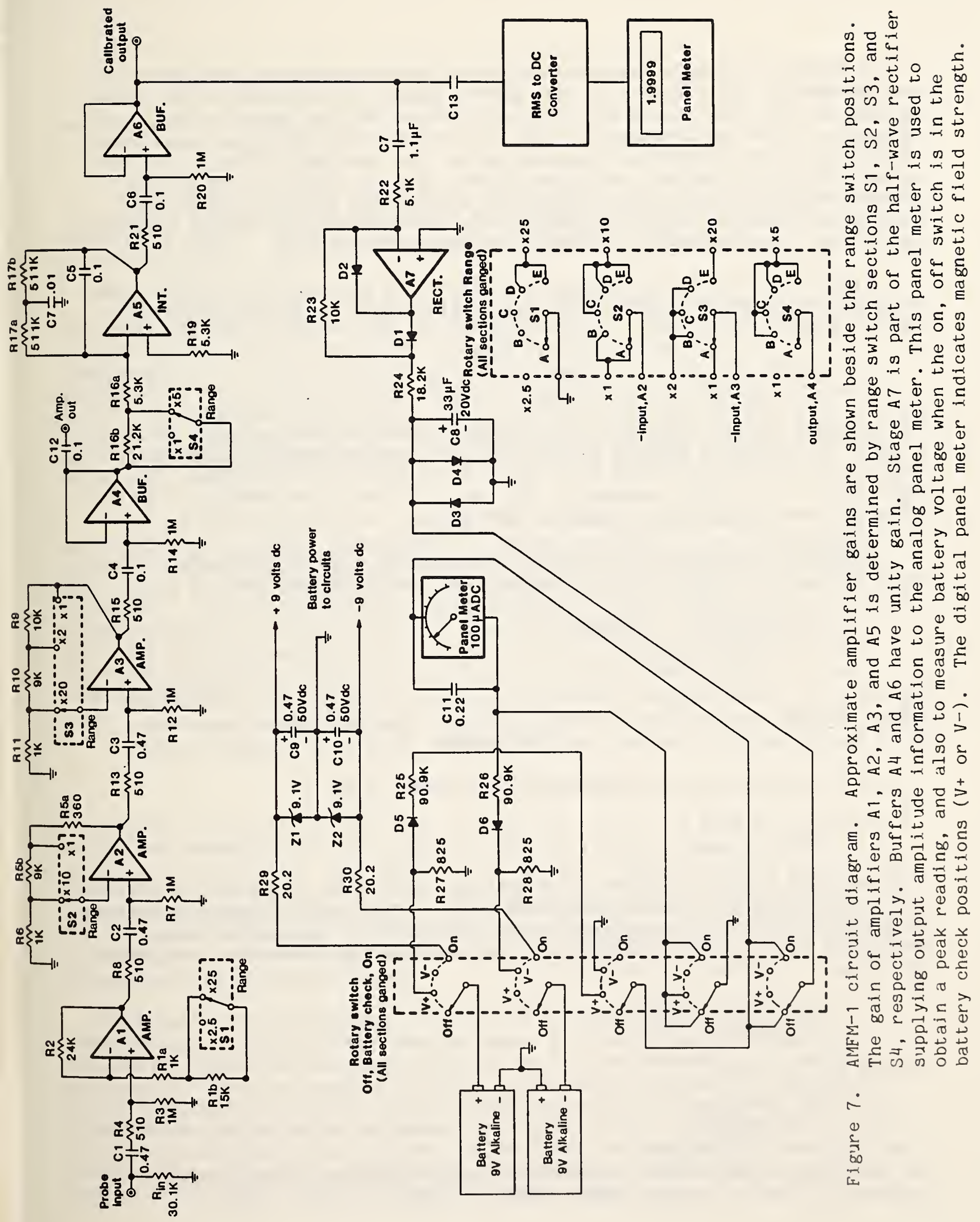


A buffer to provide impedance matching separates the last amplifier from the integrator, and a buffer is also placed between the integrator and the ac voltage output. All stages are ac coupled except for the input to the integrator. The low frequency cut of $f$ of the interstage coupling is set high enough to prevent random low frequency noise from causing a variation in the output voltage on the most sensitive ranges. The ac coupling also prevents effects from the input of set voltage and current and from the input bias current of individual amplifier stages from accumulating and causing extreme variations in the quiescent voltage of the output amplifier.

The integrator, $A 5$, is basically an inverting operational amplifier stage in which the feedback resistor has been replaced by a capacitor to produce a gain, $A_{i}$, of

$$
A_{i}=\frac{1}{\omega \cdot R 16 \cdot C 5}
$$

This assumes that R17, which is in parallel with $\mathrm{C}_{5}$, is much greater than $1 / j \omega C 5$. For ranges $B$ through $E, R 16$ is $5.3 \mathrm{k} \Omega$ and for range $A$ (highest or least sensitive) another $21.2 \mathrm{k} \Omega$ is added for a total $R 16$ of $26.5 \mathrm{k} \Omega$. The capacitor, $\mathrm{C} 5$, is a low leakage $0.1 \mu \mathrm{F}$. At $60 \mathrm{~Hz}$ the integrator gain is thus unity on range $A$ and 5.0 on ranges $B$ through $E$.

The value chosen for $C_{5}$ influences the maximum slew rate (SR) for the integrator, i.e., the time rate of change for the output voltage.

$$
S R=\left[\frac{d v_{0}}{d t}\right]_{\max }=\frac{I_{0} \max }{c 5},
$$

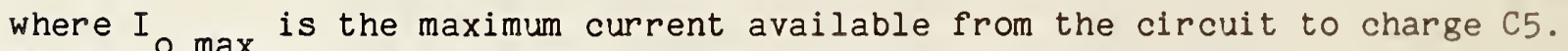
Higher volfaxge and/or higher frequency outputs require a faster slew rate. If C5 is too large, the slew rate will be reduced below an acceptable value.

At dc and very low frequencies the integrator gain is

$$
A_{i L}=-\frac{R 17}{R 16} \text {, }
$$

or simply the gain of an inverting operational amplifier. This occurs because at dc and very low frequencies the term $1 / \omega C 5$ is much greater than $R 17$ and the impedance of the parallel combination of $C 5$ and R17 is essentially the resistance of $\mathrm{R} 17$. The frequency, $f$, occurs where the integrator gain equals the dc gain, or from eqs (10) and (1\&)

$$
\frac{1}{2 \pi f_{c} \cdot R 16 \cdot C 5}=\frac{R 17}{R 16} \text {. }
$$

Solving for $\mathrm{f}_{\mathrm{c}}$ gives

$$
\mathrm{f}_{\mathrm{C}}=\frac{1}{2 \pi \cdot \mathrm{R} 17 \cdot \mathrm{C} 5}
$$

For operation in the linear integration region, the lowest frequency of interest, $f_{L}$ should be much higher than $f_{c}$, i.e., 


$$
f_{L}>\frac{1}{2 \pi \cdot R 17 \cdot C 5}
$$

and hence

$$
\mathrm{R} 17 \gg \frac{1}{2 \pi \cdot \mathrm{f}_{\mathrm{L}} \mathrm{C5}^{\mathrm{S}}}
$$

Operational amplifier stage $A 7$ is a half-wave rectifier with 224 selected so that the analog meter reads $80 \%$ of full scale for a full scale output on the digital meter. This allows an analog indication of the amount of overranging up to $125 \%$.

Two alkaline 9-volt clip-in batteries furnish power for the unit, one for the positive supply and one for the negative supply. The network R29,Z1,C9 (or $\mathrm{R} 30, \mathrm{Z2}, \mathrm{C} 10$ ) limits the battery voltage applied to the circuits to approximately 9.1 volts, thereby protecting against over-voltage from installation of incorrect battery, reverse polarity, etc. The battery check circuit is comprised of R25, R27, and D5 (or R26, R28, and D6) with R27 selected to approximate the current drain of the instrument and $R 25$ selected so that the analog meter indicates the approximate battery voltage, i.e., $80 \mu A=8.0$ volts.

Operational amplifiers A1, A4, A5, and A7 require approximately $1.2 \mathrm{~mA}$ quiescent current each. Stages A2, A3, and A6 are able to use a low current op-amp and thus require only $0.2 \mathrm{~mA}$ each. Total current drain is presently less than $6 \mathrm{~mA}$ from each battery, permitting at least 48 hours of continuous operation. Total operating time will be somewhat longer when operated intermittently. Once the rms to dc converter and digital display are added, the total current required from each battery will increase to about $8 \mathrm{~mA}$. Operating time should then be at least 36 hours continuously from a set of fresh batteries.

\section{CALIBRATION}

\subsection{General Considerations}

The instrumentation described in section 2 provides a suitable and stable method for measuring low level ambient magnetic fields. Equally important is the method by which the instrument is calibrated. Stability and a calibration traceable to a known magnetic field provide the information necessary to specify measurement uncertainty. Since stable measurement instruments are not difficult to design, it is the calibration procedure and its traceability to an absolute value that often determines how small the instrument uncertainty specification can be.

The method for generating the basic reference magnetic field, and the description of a transfer standard to establish a more easily accessable secondary calibration field are described in the next section. A secondary calibration field was necessary in this investigation because (1) generation of the basic reference magnetic field requires the use of equipment that is often in service for other purposes, (2) transit time to the site of the basic reference field and set-up time for the equipment is considerable, and (3) the basic reference field, though highly accurate, is not sufficiently uniform over an area large enough to accept the AMFM-1 probe. 
Briefly, the basic reference field is a dc magnetic field generated within a well defined solenoid. A relatively portable, highly accurate and stable magnetometer is used to measure this dc field, thereby providing calibration of that instrument for use as a transfer standard. This same instrument is then used to measure and calibrate the dc field generated by dc current flowing through a set of Helmholtz coils* which serve as the secondary or local calibration setup. The ratio of the dc magnetic field to the accurately measured dc current determines the Helmholtz coil factor.** As will be shown in the next section, this coil factor is equally applicable when the Helmholtz coils are supplied with power frequency alternating current. Thus the local ac reference magnetic field can be determined as the product of the coil factor and an accuately measured ac current through the coils.

Following its use in measuring the Helmholtz coll dc field, the transfer standard is returned to the basic reference dc field and used to remeasure that field, thereby closing the loop. Periodic comparisons, i.e., once every two to three years can be made between the basic reference field and the local calibration set up but no change should occur if the Helmholtz coil pair retains its original physical dimensions.

\subsection{Calibration Procedure for the Least Sensitive Ranges}

The dc magnetic field generated within a solenoid constructed with a relatively large number of closely spaced turns and for which the dimensions and number of turns are precisely known, can be calculated $[6,7]$. At the center of the solenoid,

$$
B_{s}=\frac{\mu_{0} I_{s}}{\left(4 a^{2}+l^{2}\right)^{1 / 2}},
$$

where $\mu$ is the permeability of a vacuum, $N$ is the number of turns through which the current $I$ passes, and $a$ and $l$ are the radius and length of the solenoid, respectivêly. Since all factors on the right side of eq (17) are constant, except current, the equation can be rewritten as

$$
\mathrm{B}_{\mathrm{s}}=\mathrm{K}_{\mathrm{s}} \mathrm{I}_{\mathrm{s}} \text {, }
$$

where $\mathrm{K}_{s}=\mu_{0} \mathrm{~N} /\left(4 \mathrm{a}^{2}+l^{2}\right)^{1 / 2}$. It is this constant which is precisely known [8]. The field, $B_{S}^{\circ}$, is the basic reference magnetic field, which can be varied by changing the value of dc current through the solenold.

*A pair of flat, circular coils having equal numbers of turns, equal diameters, arranged with a common axis, spaced one radius apart and connected in series. This design produces a relatively uniform magnetic field at the center of the structure [5].

**The Helmholtz coil factor can be computed directly from dimensions of the coil, number of turns, etc., but unless the coils are very large, the dimensional uncertainties due to the finite size of the wire bundle cause an overall uncertainty which is greater than that resulting when the coll factor is determined as described above (see section 3.4 ). 
The solenoid [8] is located in a building specifically constructed to provide a nonmagnetic environment [9]. The solenoid is oriented in a horizontal East-West direction and centered within a system of three large Helmholtz coil pairs, the individual axes of which are oriented East-West, North-South and up-down, respectively. Selective energization of each Helmholtz coil set serves to cancel the earth's magnetic field within the solenoid.

A null-type magnetometer, in which the magnetic field measured at its sensor is neutralized by a precisely calibrated current passed through a solenoid surrounding the sensor element, is used to measure the basic reference field $B$ at the center of the solenoid. The neutralizing field can be set to five significant figures ( \pm 4 digits in the last figure) with full scale sensitivity selectable between 100 and 0.025 microtesla. Measurements are made for three or four different values of $B_{s^{*}}$ A sufficient number of points are chosen so that the magnetometer can be calibrated, i.e., a specific five significant figure reading on the magnetometer is equivalent to a specific known value of the basic reference magnetic field. Accuracy of the magnetometer readout as compared to the actual field calculated from eq (18) is not particularly important for our purpose here, but stability of the magnetometer calibration is important.

The magnetometer is then moved to the local laboratory and used to measure the dc field $B_{H}^{\prime}$ generated within a set of Helmholtz coils. The Helmholtz coil pair is positioned so that the field generated will be horizontal. With no current through the coils, the Helmholtz pair and the magnetometer probe (aligned with the Helmholtz coil axis) are first rotated in the horizontal plane to minimize any ambient reading due to the earth's dc field. The coils are then energized briefly with ac current to produce a field of approximately 50 microtesla. This ac field should have essentially no effect on whatever ambient $d c$ field is present and serves to confirm that surrounding ac distribution lines and equipment do not effect the dc measurements. The next step is to move nearby equipment and again note the effect on the ambient de field. For minimum error due to iron core transformers, etc., nearby equi pment is located so that a relatively large displacement is necessary to produce a measureable change in the ambient dc field.

Any dc field measured with no current in the coils, $\mathrm{B}_{\mathrm{H}}$, is likely due either to the earth's magnetic field and/or nearby iron core transformers. This must be subtracted from the dc field measured with current in the coils, $B_{H}^{\prime}$, to arrive at the magnetic field generated by the current through the Helmholtz coils, i.e.,

$$
\mathrm{B}_{\mathrm{H}}=\mathrm{B}_{\mathrm{H}^{\prime}}-\mathrm{B}_{\mathrm{H}_{\mathrm{O}}}
$$

DC current, $I_{H}$, through the Helmholtz coils produces a magnetic field which can be accurately calculated $[5,10]$ as

$$
B_{H}=\left[\frac{8 \mu_{0} N}{5[5]^{1 / 2} r}\right] I_{H} \text {, }
$$


where $\mu_{0}$ is the permeability of a vacuum, $N$ is the number of turns on each coil, and $r$ is both the radius and/or spacing of the colls. The factors inside the brackets make up a constant called the coil factor, $\mathrm{K}_{\mathrm{H}}$. Measurement of the dc current through the coils, which generates ${ }^{H}{ }_{H}$, and measurement of $\mathrm{B}_{H}$ with the magnetometer allows an accurate computation of this coil factor. Rearranging eq (20) and substituting $\mathrm{K}_{\mathrm{H}}$ for the factors inside the brackets gives

$$
\mathrm{K}_{\mathrm{H}}=\mathrm{B}_{\mathrm{H}} / \mathrm{I}_{\mathrm{H}} \text {. }
$$

Since frequency is not a factor* in eq (20), the coll factor for ac rms currents, $K_{h}$, is the same as that for dc currents, i.e., $K_{H}=K_{h}$. An accurate determination of ac rms current through the Helmholtz colls thus allows an accurate determination of the ac rms magnetic field, $B_{h}$, generated within the Helmholtz coll pair, or

$$
B_{h}=K_{h} I_{h} \text {. }
$$

where $K_{h}=K_{H}$. It is this field, $B_{h}$, which is used to calibrate the AMFM-1 on its least sensitive ranges (ranges $A$ and $B$ ). The uncertainties involved in this calibration are discussed in section 3.4 and a worst case uncertainty specification is determined.

The calibration is accomplished in a normal laboratory, 1.e., when constructed there were no special provisions taken for reducing the amblent ac fields present. The Helmholtz coil pair is located and oriented so that the effect of the ambient magnetic field measured at the center of the Helmholtz coil pair is reduced to a minimum, but this ambient field cannot be reduced much below $0.04 \mu \mathrm{T}$. This value has negligible effect when calibrating the least sensitive range $(A)$ and the upper portion of range $B$. It becomes noticeable in the middle portion of range $B$ and significantly raises the uncertainty of calibration for range C ( $2 \mu \mathrm{T}$ full scale). The three most sensitive ranges ( $C, D$, and $E$ ) are therefore calibrated using a voltage injection technique. Both methods are used on portions of ranges $A$ and $B$ to verify the correlation of the two methods.

\subsection{Calibration Procedure for the Most Sensitive Ranges}

Calibration of the most sensitive ranges ( $C, D$, and $E$ ) is achieved by using an accurate voltage divider to inject a voltage $V_{F M}$, directly into the AMFM- 1 input terminals, thereby bypassing the pickup coll $1^{1}$ and the uncertainty caused by ambient magnetic fields in the laboratory. The voltage to be injected is determined from the AMFM-1 probe factor $k$, and the probe ractor is obtained from information recorded during the callbration procedure for the least sensitive ranges, $A$ and $B$.

*This is not true for magnetic field frequencies mych bigher than those of interest here. A correction factor equal to $\left[1-\left(f^{2} / f_{0}^{2}\right)\right]$, where $f$ is the magnetic field frequency and $f$ is the resonant frequency of the Helmholtz pair, would have to be applied $[4]$. 
The probe factor, $k_{p}$ is defined as

$$
k_{p}=\frac{p_{p}}{3_{h}} \text {, }
$$

where $\mathrm{v}_{p}$ is the rms voltage senerated at the output of the AvEM-1 probe for a Given, ris, $50-\mathrm{Hz}$, magnetic field, $B_{h}$, which is perpendicular to the plane of the probe. This voltage can be determined when the probe is positioned witnin the Helmholtz coils for calibration of the least sensitive ranges, i.e., centered with the probe axis in line with the Helmholtz coil axis. The units for $k$ are volts per tesla. The probe output voltage will change slightly when Ronnected to the AMYM-1 because of loading provided by the AMEM-1 input. The desired probe factor can thus be expressed as

$$
k_{p}^{\prime}=\frac{{ }^{v} E U_{i}}{B_{h}},
$$

where $\mathrm{v}_{E M_{i}}$ is the ras input voltage to the AMEM- ${ }^{*}$ and $B_{\text {h }}$ is defined above.

To calculate $\mathrm{k}_{\mathrm{p}}$ ', the value of $\mathrm{v}_{\mathrm{FM}}$ and the $\mathrm{B}_{\mathrm{h}}$ which causes it sho:ll be determined for three or forr different points on each of ranges $A$ and 3 . The lower end of range 3 may result in a less accurate determination because of the increasing enror caused by ambient fields. An average for $k$ ' can be calculated from the various values obtained. This average shoul not differ from the extrexes by more than the uncertainty of making the $V_{F M}$ and $B_{\text {h }}$ measurements, provided that the ac ambient pields are low relative to $3_{h}$. Uncertainties are discussed more fully in the next section. The closeness (see section 3.4) of the various values for $k^{\prime}$ indicates and confiras the linearity of the AMEM-1 probe at the nigher bagnetic fields. There is no physical reason why this same probe should not be linear at the lower magnetic fields which are weasured on ranges $C, D$, and $\Xi$.

Once the probe factor $k$ ' has been determined, a calibration check of the

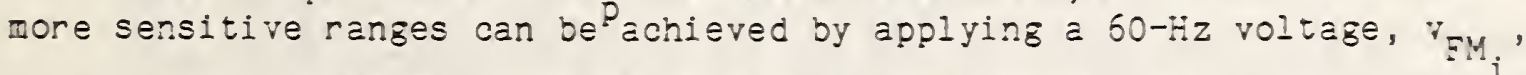
directly to the ANEM-1 input terminals and measuring the output. The can be calculated by rearranging eq (24) to give

$$
v_{F M}=k_{p}{ }^{\prime} B_{h}
$$

*liote that connecting an ac voltweter to the AMEM-1 input (in order to weasure $\mathrm{v}_{F M_{i}}$ ) causes additional loading upon the probe output, thereby reducing both $\mathrm{V}_{\text {FM }} i$ and the AMEM-1 Output meter indication from what they would be without the ${ }^{i}$ voltmeter connected. To obtain the correct value for VFM, the rielmholtz coil current and hence $B_{h}$ wust first be increased until the APrM-1 output meter indication is the same as it was before the ac voltmeter was connected to the AMFM-1 input. 
Here, $B_{h}$ represents the desired AMFM-1 output meter calibration check point. As an example, the probe factor for the present AMFM-1 probe is $3.91 \mathrm{mV} / \mu \mathrm{T}$. To check the full scale indication for range $D(0.2 \mu \mathrm{T})$, a value for $\mathrm{v}_{F M}$ of

$$
v_{F M_{i}}=\frac{3.91 \mathrm{mV} \mathrm{rms}}{\mu \mathrm{T}} \times 0.2 \mu \mathrm{T}=0.7820 \mathrm{mV} \mathrm{rms}
$$

must be inserted into the AMFM-1 input terminals. To check the full scale indication of range $\mathrm{E}$, the input voltage, $\mathrm{V}_{\mathrm{FM}_{i}}$, would be only $78.2 \mu \mathrm{V} \mathrm{rms}$.

The above examples show that the required input voltage may be too low and hence too noisy to provide either (1) a relatively clean signal for calibration purposes, or (2) a signal which can be accurately measured. For this reason a shielded voltage divider is used. The divider is composed of two accurate and stable resistors, a $10 \mathrm{k} \Omega$ upper resistor, $R_{D}$, in series with a $10 \Omega$ lower resistor, $R_{L}$, both enclosed within a shielded box. The junction of the two resistors is connected to the AMFM-1 input via a shielded connector. The divider ratio is chosen so that the ac rms voltage at the top of the divider, supplied by a sine-wave generator, is sufficiently large to be measured accurately, and noise in the signal is attenuated along with the signal. The shielded leads reduce pickup noise sufficiently to check calibration down to midscale on the most sensitive range. A diagram of the calibration setup is shown in figure 8 .

The divider ratio can be calculated as $\left(R_{L}+R_{P}\right) / R_{P}$ where $R_{p}$ is the parallel combination of $R_{L}$ and the AMFM-1 input impedance, $R_{F M}$. This latter impedance consists of $R_{\text {in }}$ (a $30.1 \mathrm{k} \Omega$ resistor) in parallel with the combination of $\mathrm{C} 1$ and $\mathrm{R} 4$ in series with the parallel configuration of $\mathrm{R} 3$ and the input impedance of $\mathrm{A} 1$ (see figure 7). The input impedance of $\mathrm{A} 1$ is at least an order of magnitude larger than the $1-M \Omega$ value of $R 3$ and can therefore be neglected. The impedance of $\mathrm{R} 4$ and $\mathrm{C} 1$ at $60 \mathrm{~Hz}$, which is at least two orders of magnitude less than R3 and even less at higher frequencies, can also be neglected. An accurate measurement of the AMFM-1 input impedance can, therefore, be made between the input and ground after removing $A 1$ and shorting across $\mathrm{C} 1$. This value is approximately $29 \mathrm{k} \Omega$. Since $R_{F M}$ is at least 2800 times greater than $R_{1}$, its presence changes the divider ratio by less than $0.04 \%$. The voltage $\forall$, obtained from a sine-wave generator, is that required at the top of the divider to produce $V_{F M_{i}}$ at the junction between $R_{D}$ and $R_{L}$.

Distributed capacitance to ground is indicated at the AMFM-1 input by $C_{F M}$ in figure 8 . This capacitance should have little effect on the divider ratio, however. A value of $15 \mathrm{pf}$ would change the divider ratio by less than $0.1 \mathrm{ppm}$ at $60 \mathrm{~Hz}$. The capacitance across $\mathrm{R}_{\mathrm{D}}$ is represented by $\mathrm{C}_{\mathrm{D}}$. A $10 \mathrm{pF}$ value for $C_{D}$ would change the divider ratio by less than $0.004 \%$ at $60 \mathrm{~Hz}$. An experiment to determine whether distributed capacitance across $R_{D}$ or $R_{L} 1 s$ affecting the divider ratio is discussed later in this section.

Assuming the effects of distributed capacitance to be negligible, 


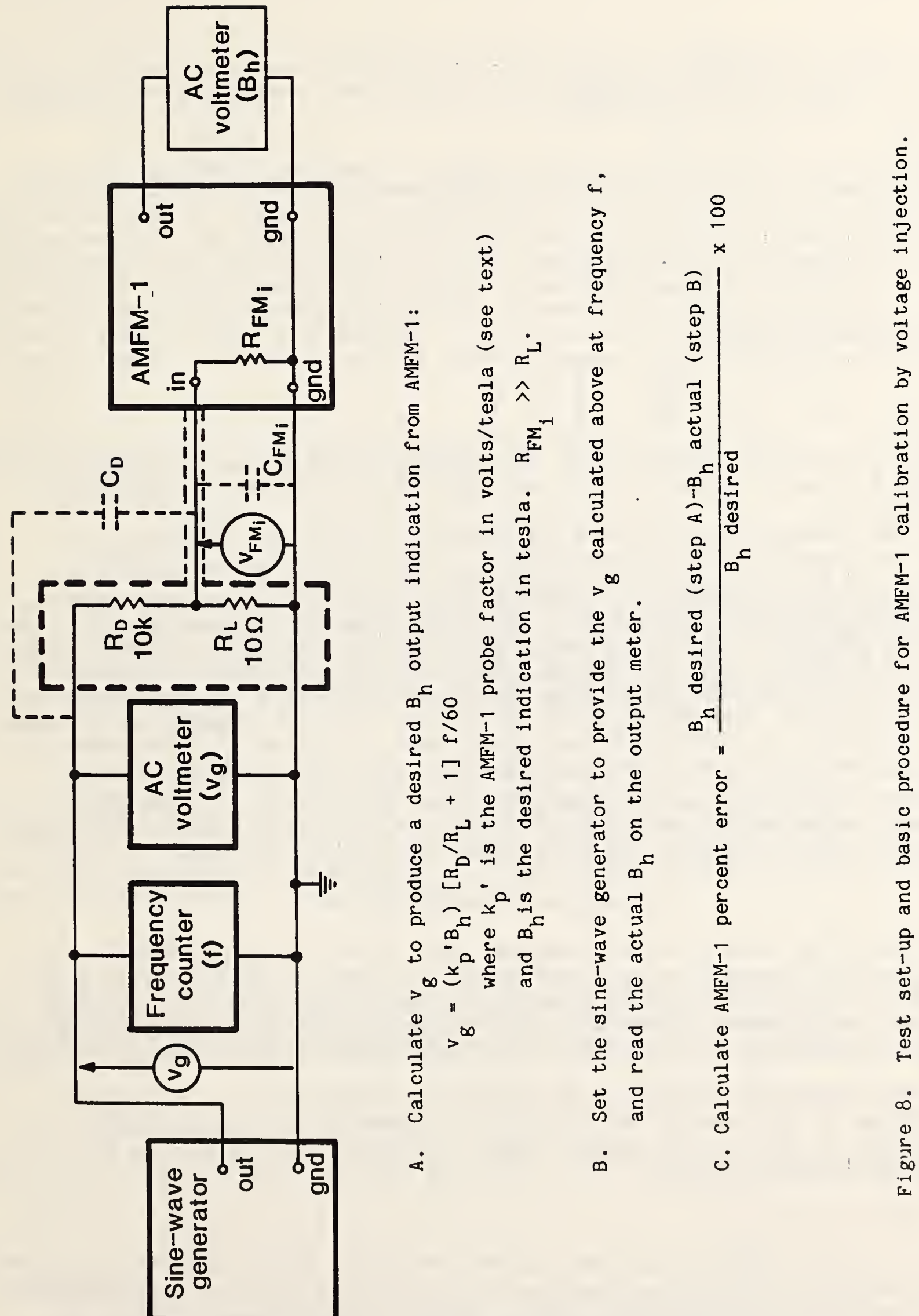




$$
v_{F M_{i}}=\frac{v_{g} R_{L}}{R_{D}+R_{L}} \times \frac{f}{60} .
$$

where $f$ is the frequency of the input signal.* Combining equations (25) and (26) yields

$$
k_{p}^{\prime} B_{h}=\frac{v_{g} R_{L}}{R_{D}+R_{L}} \times \frac{f}{60} .
$$

Solving for $v_{g}$ yields

$$
v_{g}=k_{p}^{\prime} B_{h}\left[\frac{R_{D}}{R_{L}}+1\right] \frac{60}{f},
$$

where $v_{\text {g }}$ is the rms voltage which, when applied to the top of the divider, should forroduce the magnetic field indication, $B_{h}$, on the AMFM-1 output meter.

The presence of distributed capacitance in the voltage divider ( $C_{D}$ or $C_{F M}$ in figure 8), which is sufficiently large to effect the calibration resilts, can be determined in either of two ways. One involves raising the sine-wave generator frequency to $\mathrm{f}_{2}$ and noting whether the output meter reading obtained using $f$ is exact $2 \mathrm{y} f / f$, less than the value obtained using $f_{2}$. If it is not, then distributed capacitance may be having an effect. Another method involves calculating the value for the AMFM-1 input voltage from eq (26) and then comparing the result with the value measured using an ac rms voltmeter. In doing this, the value chosen for $v$ must be large enough to enable a relatively noise free measurement of $\mathrm{v}_{F M}$ and the effect of any ac voltmeter loading across the lower part of the divider must be taken into account. Both checks were performed on the voltage divider used to calibrate the AMFM-1 and no effects from distributed capacitance were noted.

\subsection{Calibration Uncertainties}

All of the uncertainties associated with the calibration procedures just described are tabulated in this section and an overall uncertainty figure for the AMFM-1 is derived. The root-sum-of-the-squares method is used to arrive at total uncertainties except where the individual uncertainties may not be totally independent of one another. For these cases, they are added directly.

The calibration of AMFM-1, as explained in section 3.1, is ultimately referenced to the value of the dc field, B, generated within a solenold, the dimensions of which are accurately known. Squation (18) from section 3.2 gives the value of $B_{S}$ as

$$
B_{S}=K_{S} I_{S} \text {, }
$$

*The term $(\mathrm{f} / 60)$ is necessary because, as explained in section 3.1, the AMFM-1 probe provides a differentiated signal, thereby resulting in a larger probe output for magnetic field harmonic frequencies. 
where $I_{s}$ is the dc current through the solenoid and $K$ is the solenoid coil factor in tesla per ampere. From eqs (17) and (18) this factor is

$$
K_{S}=\frac{\mu_{0}}{\left(4 a^{2}+l^{2}\right)^{1 / 2}} \text {. }
$$

Allowing for variation between determinations, the value of $\mathrm{K}$ for the precision solenoid is known to an uncertainty of less than $\pm 18 \mathrm{ppm}$ or $\pm .001 \%$. The current, $I_{s}$, can be set to six decimal places by means of a precision current source and remains stable to better than \pm 1 digit in the last place. This results in a current that is stable to better than $\pm .006 \%$ of the set value for the range of currents necessary to produce dc magnetic fields of $20 \mu \mathrm{T}$ or greater within the solenoid. The absolute value of $\mathrm{I}_{\mathrm{s}}$ is determined by measuring the voltage it develops across a series precision resistor, or

$$
I_{S}=V_{s} / R_{S}
$$

Substituting eq (31) into eq (29) gives

$$
B_{S}=K_{S} \frac{V_{s}}{R_{S}} .
$$

The uncertainty in the value of the precision resistor, allowing for temperature variation due to environment and/or power dissipation, is less than $\pm .01 \%$. The voltage can be measured using a dc voltmeter with a one year uncertainty over a temperature range of 15 to $25^{\circ} \mathrm{C}$ of $< \pm .008 \%$ of reading at full scale and $< \pm .01 \%$ of reading at one tenth scale. Applying the boldfaced uncertainties to eq (32) results in an uncertainty of $\leq \pm .015 \%$ for $B_{s}$ at the center of the solenoid.

Three or four different values of $B_{\text {s }}$ are measured with an accurate and stable magnetometer, thus calibrating the magnetometer as a transfer standard. The transfer standard is used to measure the dc field, $B_{H}$, generated by a set of Helmholtz coils which are located in a more readily accessable location for calibrating the AMFM-1 (see section 3.2). The Hemholtz dc coil factor $K_{H}$ is then calculated from eq $(21)$, section 3.2 as

$$
\mathrm{K}_{\mathrm{H}}=\mathrm{B}_{\mathrm{H}} / \mathrm{I}_{\mathrm{H}} \text {. }
$$

As discussed in section 3.2, the dc and ac coil factors for the Helmholtz coil are identical $\left(K_{H}=K_{h}\right)$; hence once $K_{H}$ is known, the value of the ac rms magnetic field generated within the Helmholtz coils can be calculated from eq (22)

$$
B_{h}=k_{h} I_{h} \text {, }
$$

where $I_{h}$ is the rms current through the coils. This current is determined by

$$
I_{h}=V_{h} / R_{h} \text {, }
$$

where $V_{h}$ is the rms voltage, developed across a precision resistor, $R_{h}$, in series with $I_{h}$.

The uncertainties connected with the magnetometer measurement of $B_{S}$ (not the uncertainty of the actual field value present which was discussed eărlier 
in this section) are due to (1) error in centering the probe within the solenoid, (2) averaging of $B_{\text {s }}$ over the sensing area of the probe, and (3) instability within the magnetometer itself.

The size of the sensing area for the magnetometer probe used is approximately $6 \mathrm{~cm}$ long by $1.5 \mathrm{~cm}$ square. Combining placement error (1) with finite sensor size (2) results in the center of the sensing area having a maximum displacement of perhaps $\pm 3 \mathrm{~cm}$ away from the solenoid center along its axis and perhaps $\pm 2 \mathrm{~cm}$ away perpendicular to the solenoid axis. The field within a solenoid at any point away from its center along the axis may be computed as $[7,11]$

$$
B_{S}=\left[\frac{\mu_{0} N}{\ell}\right] \frac{I_{S}}{2}\left[\cos \theta_{1}+\cos \theta_{2}\right] \text {, }
$$

where $\mu_{0}, N, l$ and $I_{s}$ have all been defined earlier and $\theta_{1}$ is the angle formed between the axis and ${ }^{s}$ line connecting one edge of the coll to the point, $P$, in question, and $\theta_{2}$ is the angle formed between the axis and a line connecting the other edge of the coil to the same point (see the diagram of fig. 9). At $3 \mathrm{~cm}$ from the center along the axis of a 1000 turn solenoid, one meter long and $28 \mathrm{~cm}$ in diameter, the field calculated from eq (36) is approximately $0.04 \%$ smaller than the value at the center. Since the sensor averages over its entire $6 \mathrm{~cm}$ sensing length, the latter figure is used as a worst case.

Calculation of the error due to probe displacement perpendicular to the solenoid axis is more complicated. However, shifting of the probe within the solenoid showed experimentally that (for the maximum displacements indicated earlier) the error due to displacement along the axis is large compared to the error due to displacement perpendicular to the axis and the latter can be neglected.

Stability of the magnetometer transfer standard has been shown to be of the same order of magnitude as the uncertainty in the reference field itself $(0.015 \%)$, i.e., there was less than $0.02 \%$ difference between readings taken one month apart during which time the magnetometer was transferred to the local calibration site and then returned to the reference field generated by the solenoid.

Total uncertainty in the magnetometer measurement of the known solenold generated field, $B_{s}$, (and hence the uncertainty in the calibration of the magnetometer for its use as transfer standard) can be calculated in the worst case, using the uncertainties in bold type above, as

$$
\left[(0.015 \%)^{2}+(0.02 \%)^{2}\right]^{1 / 2}+0.04 \%=0.065 \%,
$$

i.e., the calibration factor for the magnetometer has an uncertainty of $\pm 0.065 \%$ 。

From eq (20), section 3.2, the dc field produced at the center of the Helmholtz coil pair is

$$
B_{H}=\left[\frac{8 \mu_{0} N}{5[5]^{1 / 2} r}\right] I_{H} \text {, }
$$




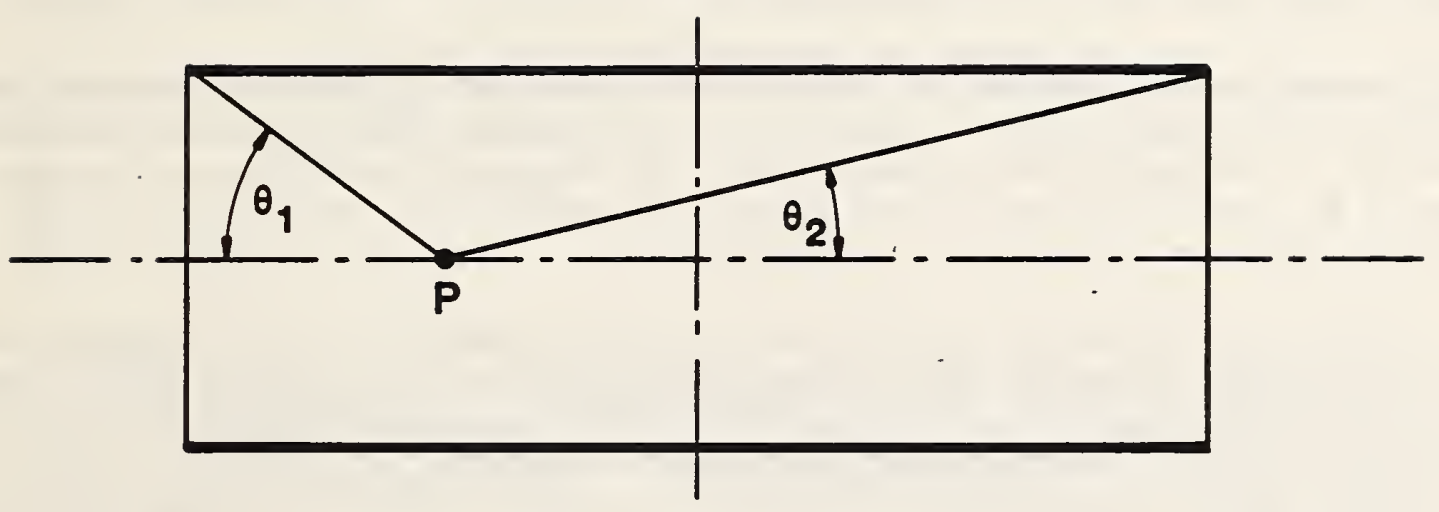

Figure 9. Angles formed between the axis of a solenoid and lines joining a point, $P$, along the axis to the outer edges of the solenoid. 
where the factor in the bracket is the Helmholtz coil factor $K_{H}$ or $K_{h}$. Rearranging (37) allows $\mathrm{K}_{\mathrm{H}}$ to be determined as

$$
\mathrm{K}_{\mathrm{H}}=\mathrm{B}_{\mathrm{H}} / \mathrm{I}_{\mathrm{H}} \text {, }
$$

where $\mathrm{B}_{\mathrm{H}}$ is measured with the magnetometer, and dc current through the coils is determined by measuring the dc voltage, $V_{H}$, across a precision series resistor, $\mathrm{R}_{H}$. Then

$$
\mathrm{K}_{\mathrm{H}}=\frac{\mathrm{B}_{\mathrm{H}} \mathrm{R}_{\mathrm{H}}}{\mathrm{V}_{\mathrm{H}}} \text {. }
$$

Four or five different $I_{H}$ vs $B_{H}$ measurements are made to arrive at an average value for $\mathrm{K}_{\mathrm{H}}$.

The uncertainties involved in the determination of $B_{H}$ are due to (1) the uncertainty of the magnetometer calibration, previously determined as $\pm 0.065 \%$, (2) the error in centering the probe within the Helmholtz coil pair, (3) the averaging of $B_{H}$ over the area of the probe, (4) ambient dc fields within the area, and (5) reading error in the magnetometer.

The combined uncertainty due to possible misplacement of the magnetometer probe in the Helmholtz coils, and to averaging over the area of the probe was found by experimentation, i.e., moving the probe by measured amounts, to be approximately $\pm 0.22 \%$. The combined uncertainty was also calculated (see the Appendix) and found to be $\pm 0.24 \%$. The latter figure is used. Either figure is a significant portion of the total uncertainty and could be reduced by construction of a larger set of Helmholtz colls. The uncertainty due to ambient dc fields is of course largest at the lowest calibrating fields used but does not exceed $\pm 0.05 \%$. Reading error in determining the magnetometer null, i.e., the variation in the null point, is less than $\pm 0.1 \%$. The root sum of the above boldfaced uncertainties results in a $\pm 0.265 \%$ uncertainty in $B_{\mathrm{H}}$.

The uncertainty in the measurement of $V_{H}$ using an accurate digital voltmeter* is less than $\pm 0.01 \%$ provided $R_{H}$ is selected to keep $V_{H}$ within the upper portion of the voltmeter range. A Iarger value for $R_{H}$ is thus used when $I_{H}$ is reduced to produce lower values of $B_{H}$.

Standard resistors with uncertainties less than $\pm 0.01 \%$ were used for $R_{H}$ with values of $1.0 \Omega, 10.0 \Omega$, and $100.0 \Omega$ and maximum currents of $0.3,0.1$, and $0.03 \mathrm{~mA}$ respectively. A $0.1 \Omega$ fan-cooled resistor with $\pm 0.03 \%$ uncertalnty and capable of passing 5 to 10 amperes was used when current in this range was necessary to produce Helmholtz coil fields in the 100 to $200 \mathrm{microtesla} \mathrm{range.}$

Using the worst case resistor uncertainty and the uncertainties previously determined for $B_{H}$ and $V_{H}$, the uncertainty in determination of the dc Helmholtz coil factor, $\mathrm{K}_{\mathrm{H}}^{\mathrm{H}}$, from ${ }^{\mathrm{H}}$ eq (39) is thus

*Several different manufacturers produce instruments with a specified dc voltage measurement uncertainty of less than $\pm 0.01 \%$. 


$$
\left[(0.265 \%)^{2}+(0.01 \%)^{2}+(0.03 \%)^{2}\right]^{1 / 2} \text { or } \pm \underline{0.27 \%} \text {. }
$$

The coil factor, $\mathrm{K}_{\mathrm{H}}$, can also be calculated from

$$
\mathrm{K}_{\mathrm{H}}=\frac{8 \mu_{\mathrm{o}}{ }^{\mathrm{N}}}{5[5]^{1 / 2} \mathrm{r}} \text {, }
$$

where $N$ is the number of turns wrapped on each coil and $r$ is the radius (or spacing) of the coils (see the discussion involving eq (20)). Because of the difficulty in measuring either $N$ or $r$ exactly, however, eq (40) serves mainly as an approximate check of the value for $\mathrm{K}_{\mathrm{H}}$.

Since the $d c$ and ac coil factors are identical $\left(K_{H}=K_{h}\right)$, the ac field, $B_{h}$, produced by ac current, $I_{h}$, through the Helmholtz coil pair can now be determined from eq (22). A specific calibration field for the AMFM-1 is set by adjusting $I_{h}$. This current is determined by measuring the ac rms voltage, $V_{h}$ it produces across an accurately known series resistor, $R_{h}$. The equation for determining $B_{h}$ thus becomes

$$
B_{h}=\frac{k_{h} v_{h}}{R_{h}} \text {. }
$$

As noted earlier, the uncertainty in $k_{h}$ (same as $K_{H}$ ) is less than $\pm 0.27 \%$. The uncertainty in the measurement of the ac $r$ ms voltage, $V_{h}$, across the series resistor is ordinarily somewhat larger than it is for the $\mathrm{h}^{\prime}$ measurement, $\mathrm{V}_{\mathrm{H}}$. The uncertainty in the ac measurement will also normally depend more upon what portion of the range is used for the measurement. Worst case total uncertainty for the ac rms instrument used was $\pm 0.18 \%$ (this occurred at a voltage just above that which would give a full scale indication on the more sensitive range immediately below).

The resistor used for $R_{n}$, whether $0.1 \Omega$ or $1.0 \Omega$, has a temperature coefficient less than $2 \mathrm{ppm} /{ }^{\circ} \mathrm{C}$, a frequency response that goes well beyond the $20 \mathrm{kHz}$ required in this application, unmeasureable self-generated noise and excellent long term shelf and load life stability. The uncertainty in the resistance value over the operating conditions can conservatively be put at less than $\pm 0.03 \%$. The uncertainty in the value of $B_{h}$ at the center of the Helmholtz coil structure and parallel to the coils axis, as determined by eq (41), is thus less than

$$
\left[(0.27)^{2}+(0.18)^{2}+(0.03)^{2}\right]^{1 / 2} \text { or }< \pm 0.33 \% \text {. }
$$

The AMFM-1 is calibrated by placing its donut-shaped probe at the center of the Helmholtz coil pair with the plane of the probe perpendicular to the coil axis. The sources of calibration uncertainty are due to (1) the aforementioned uncertainty in the determination of $B_{h}( \pm 0.33 \%)$, (2) the ambient ac magnetic field present, (3) the variation in $B_{h}$ from its central value over the area of the probe, (4) possible misalignment of the probe from its intended central position within the coils, and (5) the AMFM-1 output meter readout uncertainty.

As indicated in section 3.2, the Helmholtz coil is positioned for minimum ambient ac magnetic field within the coll but some ambient will be present. 
During the initial calibration of AMFM-1, the ac rms ambient magnetic field varied between approximately 20 and $60 \mathrm{nT}$. Using an average $40 \mathrm{nT}$ figure, the uncertainty in $B_{\text {p }}$ caused by the ac ambient field is $\pm 0.04 \%$ at $100 \mu \mathrm{T}$ (midscale on range $A$ ) and $\pm 0.4 \%$ at $10 \mu \mathrm{T}$ (midscale in range $B$ ).

The effects of the uncertainty due to items (3) and (4) above, can be combined and have been determined to be $\pm 0.24 \%$ (see Appendix $B$ ). The uncertainty in reading the AMFM-1 digital output is \pm 1 digit or $0.005 \%$ at full scale, $0.01 \%$ at midscale, and $0.05 \%$ at $10 \%$ of full scale. Using the bold faced uncertainty figures given above, the total uncertainty for the AMFM-1 calibration at midscale on the $B$ range $(10 \mu \mathrm{T})$ is thus

$$
\left[( \pm 0.33)^{2}+( \pm 0.4)^{2}+( \pm 0.24)^{2}+( \pm 0.01)^{2}\right]^{1 / 2}=\leq \pm 0.57 \%
$$

of a midscale magnetic field reading.

The uncertainty due to the ambient magnetic field $( \pm 0.4 \%)$ is obviously the largest contributor to the overall uncertainty of the AMFM-1 calibration. With negligible ambient field, the uncertainty of calibration for all ranges would simply be the uncertainty in the value of the calibrating fleld, $B_{h}$, plus the AMFM-1 probe position uncertainty and the meter readout uncertainty. Using the worst case for peter readout uncertainty, this calculates as $\left[(0.33)^{2}+(0.24)^{2}+(0.05)^{2}\right]^{1 / 2}=0.41 \%$. Adding the percent uncertainty gased by a $0.04 \mu \mathrm{T}$ ambient field, results in $\left[(0.41)^{2}+[(0.04 / 100) \times 100]^{2}\right]^{192}$ or $0.412 \%$ uncertainty of calibration at $100 \mu \mathrm{T}$, i.e., the amblent effect is negligible on the least sensitive range. Adding the percentage of yncertainty in the ambient fielg to a $2 \mu \mathrm{T}$ calibrating field results in $\left[(0.41)^{2}+\right.$ $\left.[(0.04 / 2) \times 100]^{2}\right]^{\dagger / 2}$ or $2.04 \%$ uncertainty of calibration at $2 \mu \mathrm{T}$ (10\% of full scale on the $B$ range or full scale on the $C$ range). Because of the growing uncertainty in directly calibrating the more sensitive ranges, the AMFM- 1 is calibrated by voltage injection on these ranges, as explained in section 3.3 .

The total uncertainty of the AMFM-1 calibration using voltage injection includes uncertainties (1) in determining the AMFM-1 probe factor, $k$, (2) in determining the voltage divider ratio, (3) in setting the generator Prequency, (4) in measuring the generator output voltage, and (5) due to the nolse present at the AMFM- 1 input.

The probe factor (the rms voltage output from the probe for a 81 ven $60 \mathrm{~Hz}$ ac magnetic field applied perpendicular to the plane of the probe), miltiplied by the resistive divider ratio, the desired magnetic field indication on the AMFM- 1 meter, and the ratio of $60 \mathrm{~Hz}$ to the calibrating signal frequency gives the voltage required at the input to the divider to produce the correct calibrating signal at the AMFM-1 input. See section 3.3 and eq (28) which, for convenience, is reproduced below:

$$
v_{g}=k_{p}^{\prime}\left[B_{h} \frac{R_{D}}{R_{F M_{1}}}+1\right] \frac{60}{f} .
$$

The probe factor, $k^{\prime}$, is computed from information gathered during calibration of the less Sensitive AMFM-1 ranges while using the Helmholtz coll to produce the calibrating field. The uncertalnties involved in determining $\mathrm{k}_{\mathrm{p}}{ }^{\prime}$ are (1) in the voltage measurement of the ac rms signal from the probe, 
(2) in determination of the Helmholtz coil ac magnetic field which produces this voltage, and (3) in positioning the probe correctly within the field so that it records the field determined in (2). Item (1) is simply the previously determined worst case uncertainty of the ac rms voltmeter reading $( \pm 0.18 \%)$. Item (2) uncertainty has already been calculated to be $\pm 0.33 \%$ with an additional $\pm 0.4 \%$ due to possible presence of ac ambient fields. Item (3) uncertainty was determined (see the Appendix) to be $\pm 0.24 \%$. This results 1 in an uncertainty for $k^{\prime}$ of $\left[( \pm 0.18 \%)^{2}+( \pm 0.33 \%)^{2}+( \pm 0.40 \%)^{2}+( \pm 0.24 \%)^{2}\right]^{1 / 2}=$ $\pm 0.60 \%$. As indicatel in section 3.3, the value for $k^{\prime}$ ' to be used in eq (42) is calculated from the average of four or five determinations at different magnetic field values. This average should not differ from the extremes by more than the $\pm 0.60 \%$ maximum uncertainty in the determination of each individual value. If it does, the additional error should be added to obtain the total uncertainty in the value of $k_{p}{ }^{\prime}$.

The uncertainty in the resistor divider ratio $\left[R_{D} / R_{L}+1\right]$ is a function of how accurately the absolute value of the resistances can be measured. Accuracy is increased by using a highly stable ohmmeter for which a correction factor has been computed. Ohmmeter stability is not always specified but can safely be assumed to be greater than the stated uncertainty of the instrument. A 6-1/2 digit, 4-terminal meter which can integrate over 100 power 1 ine cycles and which has an uncertainty of less than $\pm 0.006 \%$ (for resistance values below $1.2 \mathrm{M} \Omega$ ) was used. A correction factor for the meter was determined by using the meter to measure a $\pm .002 \%$ standard resistor of approximately the same value as those used to make up the divider resistors and then dividing the standard value by the measured value. This correction factor, which is as accurate as the standard resistor (assuming meter stability to be of the same order of magnitude) is then applied to subsequent resistance measurements made in that range during the same day. This enables absolute resistance values to be obtained with an uncertainty of, at most, $\pm 0.004 \%$ of the corrected value, and the divider ratio uncertainty to be calculated as $\left[( \pm .004)^{2}+( \pm .004)^{2}\right]^{1 / 2}= \pm .0057 \%$.

The generator frequency, $f$, can be measured with any reasonably good counter to an uncertainty of less than $\pm 0.02 \%$. There is no uncertainty connected with $B_{h}$ since it is the selected value of the ac rms magnetic field that the calculated value of $v_{\text {f }}$ (from equation (42), and applied in the manner of figure 8 ) is supposed to produce on the AMFM-1 output meter. Using the boldfaced uncertainties from above, the value for $v$ can
thus be calculated with an uncertainty of $\left[(0.60)^{2}+(0.0057)^{2}+(8.02)^{2}\right]^{1 / 2}=$
$\pm 0.60 \%$. The uncertainties in determining the divider ratio and frequency are seen to be small compared to that in determining the probe factor, $\mathrm{k}_{\mathrm{p}}$ '.

Once the appropriate value for $\mathrm{v}$ is determined (within the above calculated uncertainty) it must still $1^{8}$ be measured. The uncertainty of this measurement, plus the effect of inherent noise at the divider output (input to AMFM-1) must be added to obtain a total uncertainty of calibration using voltage injection.

The $k$ ' for the current AMFM-1 probe is 3.91 millivolts per microtesla and the voltage divider ratio $\left(R_{D} / R_{F M}+1\right)$ is 693.1 . Using eq (42) to calculate $v_{g}$, for $60 \mathrm{~Hz}$, a value of $27.1 \mathrm{mV}$ is required for $a B_{h}$ indication of 
$10 \mathrm{nT}$ (midscale on the most sensitive range) and $5.4 \mathrm{mV}$ for a $\mathrm{B}_{\mathrm{h}}$ indication of 2 nT (10\% of full scale on the most sensitive range).

An ac rms voltmeter with a 200-mV full-scale-range was used to measure $v$ with an uncertainty less than $\pm 0.2 \%$ for $v_{\text {g }}$ equal to or exceeding $20 \mathrm{mV}$. Beloh this value, the uncertainty increases because of absolute uncertainty in the last two digits of the display, i.e., a 5-1/2 digit meter with a lowest range of $200 \mathrm{mV}$ full scale providing an accuracy of $0.1 \%$ of reading plus 20 digits will result in an uncertainty of $\pm 0.2 \%$ at $20 \mathrm{mV}$, but $0.3 \%$ at $10 \mathrm{mV}$ and $0.5 \%$ at $5 \mathrm{mV}$.

The percentage uncertainty due to inherent noise at the AMFM-1 input is calculated by taking the ratio of the noise present at the AMFM-1 input to the AMFM-1 input voltage required for calibration. (At $60 \mathrm{~Hz}$, the AMFM-1 input voltage required to produce $B_{h}$ is simply $k^{\prime} B_{h}$ ) A typical value for inherent noise during the AMFM-1 calibration was 1.3 microvolts, resulting in negligible uncertainty at midrange on range $C(1.0 \mathrm{mG})$, but increasing to $0.33 \%\left[1.3 \times 10^{-6} \div 6\left(3.91 \times 10^{-3} \underline{x}_{3} 0.1\right)\right]$ at midrange on range $D(0.1 \mu \mathrm{T})$ and to $1.66 \%\left[1.3 \times 10^{-6} \div\left(3.91 \times 10^{-3} \times 0.02\right)\right]$ at the upper end of range $E$ $(0.02 \mu \mathrm{T})$.

Total uncertainty of the voltage injection calibration for midrange on $C$ $(1.0 \mu \mathrm{T})$, midrange on $\mathrm{D}(0,1,4 \mathrm{~T})$, and the upper end of $\mathrm{E}(0.02 \mu \mathrm{T})$ is therefore $\left[(0.60)^{2}+(0.2)^{2}\right]^{1 / 2}= \pm 0.63 \% ;\left[(0.60)^{2}+(0.2)^{2}+(0.33)^{2}\right]^{1 / 2}=$ $\pm 0.71 \%$; and $\left[(0.60)^{2}+(0.2)^{2}+(1.66)^{2}\right]^{142}= \pm 1.78 \%$, respectively.

Calibration uncertainties remain below $\pm 1 \%$ for measurements of magnetic field down to $50 \mathrm{nT}$ (ranges A through the upper $75 \%$ of $\mathrm{D}$ ) and below $\pm 2 \%$ for measurements down to $15 \mathrm{nT}$ (upper end of Range $E$ ).

Calibration uncertainties due to inherent noise from the voltage injection divider increase to about $\pm 15 \%$ at the lower end of range $E$. Under operating conditions, however, inherent noise is not a problem because of the low source impedance of the AMFM-1 probe. Because of this and the fact that a check of range $E$ made at higher voltage levels showed range $E$ to be as linear as the others, there appears to be no reason why measurements down to $2 \mathrm{nT}$ (lower end of Range $E$ ) cannot be made with an uncertainty of $\pm 2 \%$ of the indicated value. Performance of the calibration in a shielded room might reduce inherent noise sufficiently so that a calibration check could be performed at the lower end of range $E$. This was not attempted.

\section{SAMPLE MEASUREMENTS}

This section provides a sample of some ambient magnetic field measurements made with the AMFM-1 and its accompanying equipment. Measurements were performed in three general locations; a laboratory, an office, and a home. The results consist of (1) the AMFM-1 4-1/2 digit rms indication of the maximum magnetic field in a given area, (2) an oscllloscope time domain representation of the field, and (3) a spectrum analyzer frequency domain representation of the field. Items (2) and (3) are reproduced in figures 11 through 19 and item (1) is included in the figure captions for item (2). Both oscilloscope and spectrum analyzer are connected to the output of the AMFM-1. All of the above measurements are made after integration of the signal within the AMFM-1 and as such are a true representation of the ambient magnetic field present (see section 2.1). 
A small, light-weight, battery-operated oscilloscope will normally be used with the AMFM-1 to produce the time domain representation of the field. For this report, however, a larger screen size and hence larger photographs for easier viewing was achieved through use of an ac powered oscilloscope. The oscilloscope was located at some distance from the measurement location so as to not, of itself, affect the ambient field located there. The approximately 6 meters of coaxial cable required to transfer signal between the AMFM-1 and the oscilloscope produced a total capacitance to ground of about $600 \mathrm{pf}$. Even at the highest frequency of interest, however $(-3 \mathrm{kHz})$, this added capacitance causes negligible loading on the output impedance of the AMFM-1.

The spectrum analyzer is a battery-operated device which did not introduce measureable additional magnetic field even when located within 1.5 meters of the measurement site. Because of a temporary defect, the base line or zero of the spectrum analyzer display was not adjustable to the bottom line of the display graticule. A calibration curve, reproduced in figure 10 , was therefore prepared and used to obtain correct amplitudes, e.g., an indication of 0.7 on the linear vertical scale is actually 0.715 , and an indication of zero is actually 0.045 .

Both absolute and relative indications produced by the spectrum analyzer are shown in the figures. For the absolute indications, the rms value of each harmonic can be determined from the vertical scale, after applying the correction indicated in figure 10. For the relative indications, the $60 \mathrm{~Hz}$ fundamental signal is adjusted to 1.0, thus allowing the percentage of other harmonics to be determined from the vertical scale.

The laboratory ambient measurements were taken at the center of the Helmholtz coil pair used for AMFM-1 calibration (coil not activated) with the fluorescent lights immediately overhead both on (fig. $\overline{11 a}$ through $11 \mathrm{c}$ ) and of $\mathrm{f}$ (fig. 12a through 12c). The office ambient measurement were taken in a room with metal walls at a position approximately $140 \mathrm{~cm}$ from the nearest wall and $80 \mathrm{~cm}$ from the front of a computer terminal/disk drive combination. Measurements were made with the terminal/disk drive both on (fig. 13a through $13 \mathrm{c}$ ) and off (fig. 14a through 14c).

The ambient measurements in a house were taken: (1) in a bedroom at a location $30 \mathrm{~cm}$ from, and on the same level with, a section of unloaded $120 \mathrm{~V}$ ac branch circuit wiring located within the wall (fig. 15a through 15c); (2) in front of and $60 \mathrm{~cm}$ from a family room 26-inch television set, both with the TV on (fig. 16a through 16c), and of ( $\mathrm{fig} .17 \mathrm{a}$ and $17 \mathrm{~b}$ ); and (3) $15 \mathrm{~cm}$ from the right front of a kitchen microwave oven, both with the microwave on ( $f i g$. $18 \mathrm{a}$ through 18c) and off (fig. 19a through 19c).

It should be emphasized that the above test situations were selected to evaluate the performance of the measurement system under typical applications. No effort was made to determine whether or not specific nearby field generating equipment or systems were typical of a class of devices; this means, for example, that no effort was made to assure that the television set used in this study was "typical." 


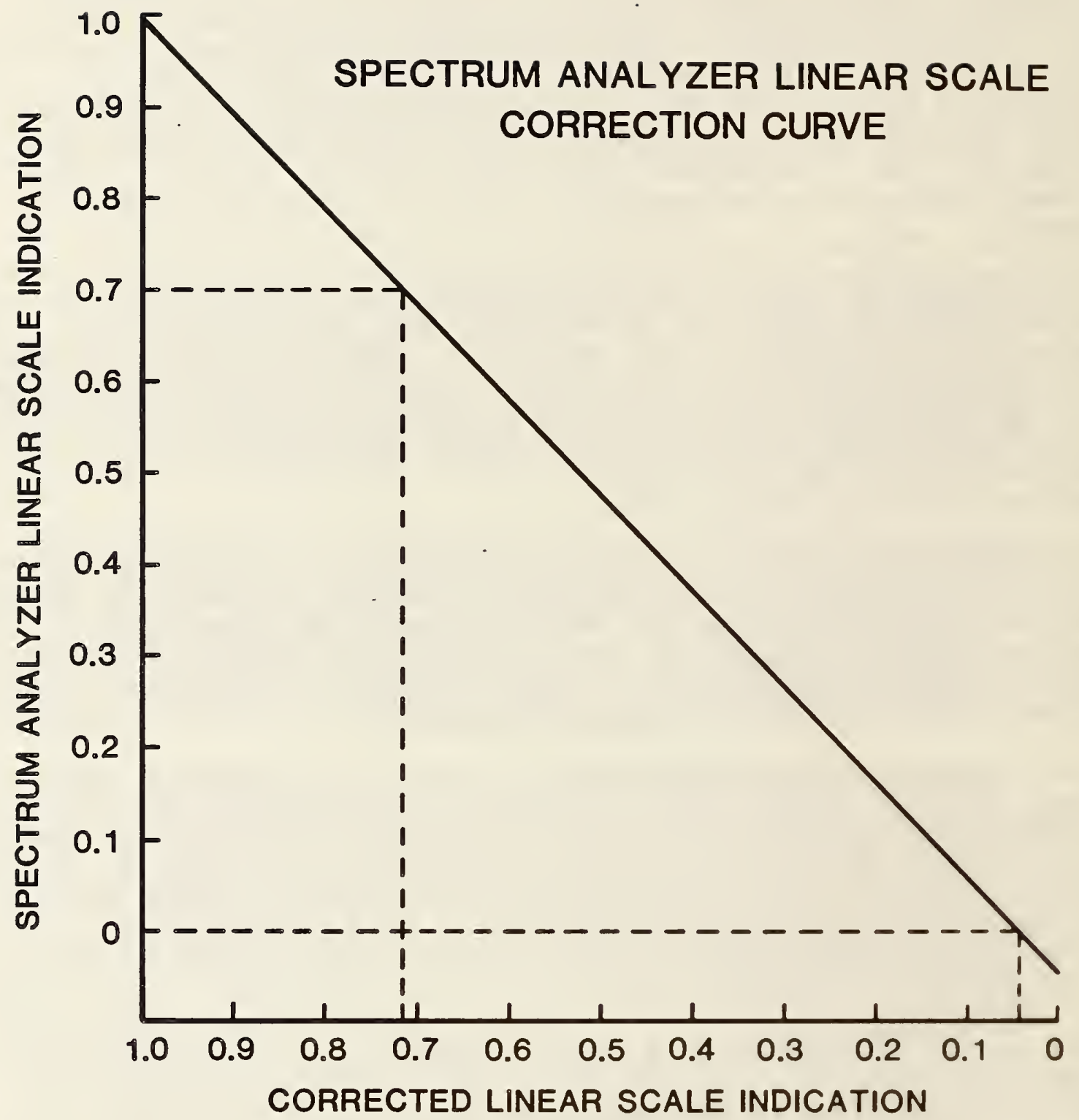

Examples: An indication of 0.7 on the linear vertical scale is actually 0.715 . An indication of zero on the vertical scale is actually 0.045 .

Figure 10. Spectrum analyzer vertical scale correction. 


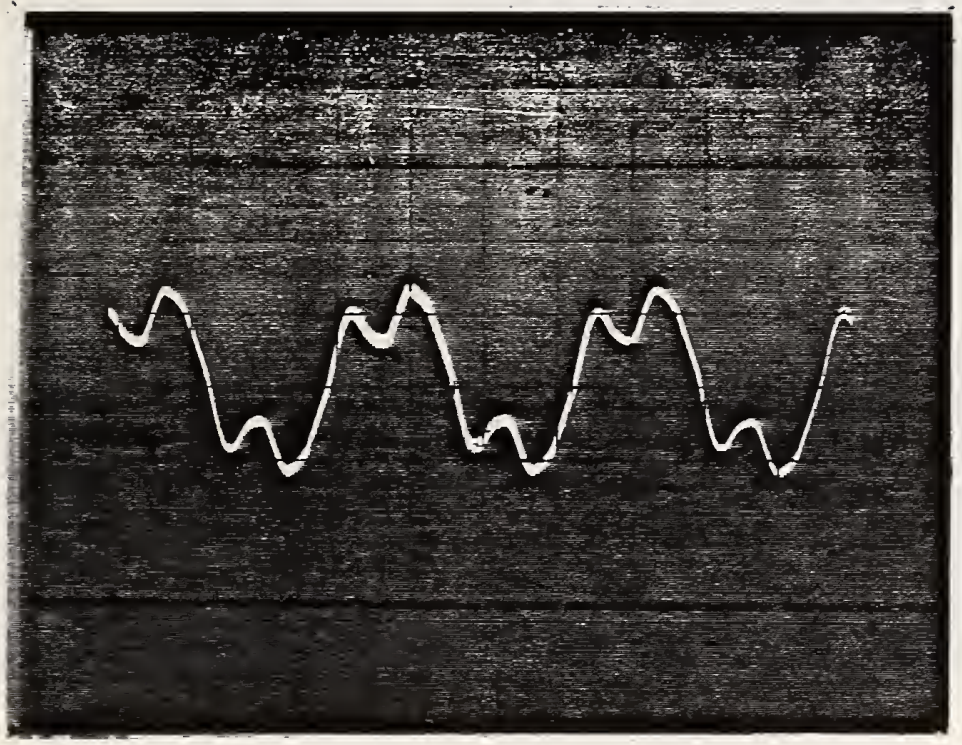

Figure 11a. Oscilloscope display of laboratory ambient magnetic field waveform. Overhead fluorescent lights on. AMFM-1 indication $=42 \mathrm{nT}$ rms. Vertical scale $=50 \mathrm{nT} / \mathrm{div}$. Horizontal scale $=5 \mathrm{~ms} / \mathrm{div}$.

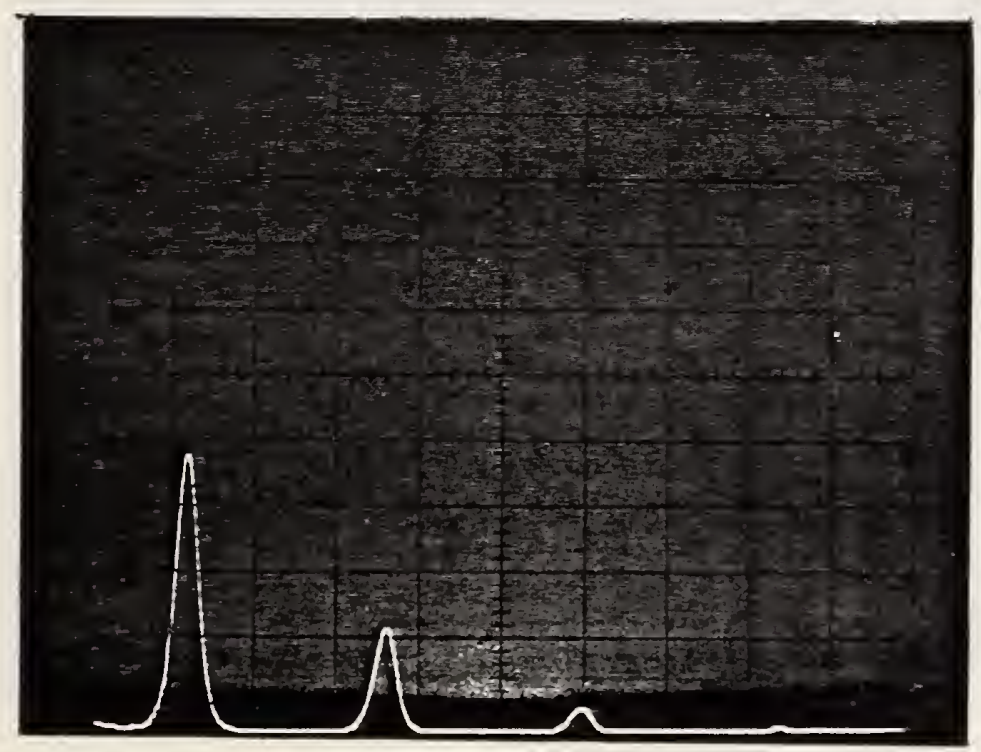

Figure $11 \mathrm{~b}$. Absolute scale spectrum analyzer display of figure $11 \mathrm{a}$ waveform showing the signiflcant harmonics to be the first, third, and flfth. Vertical scale $=10 \mathrm{nT} / \mathrm{div}$. Horizontal scale $=50 \mathrm{~Hz} / \mathrm{div}$. 


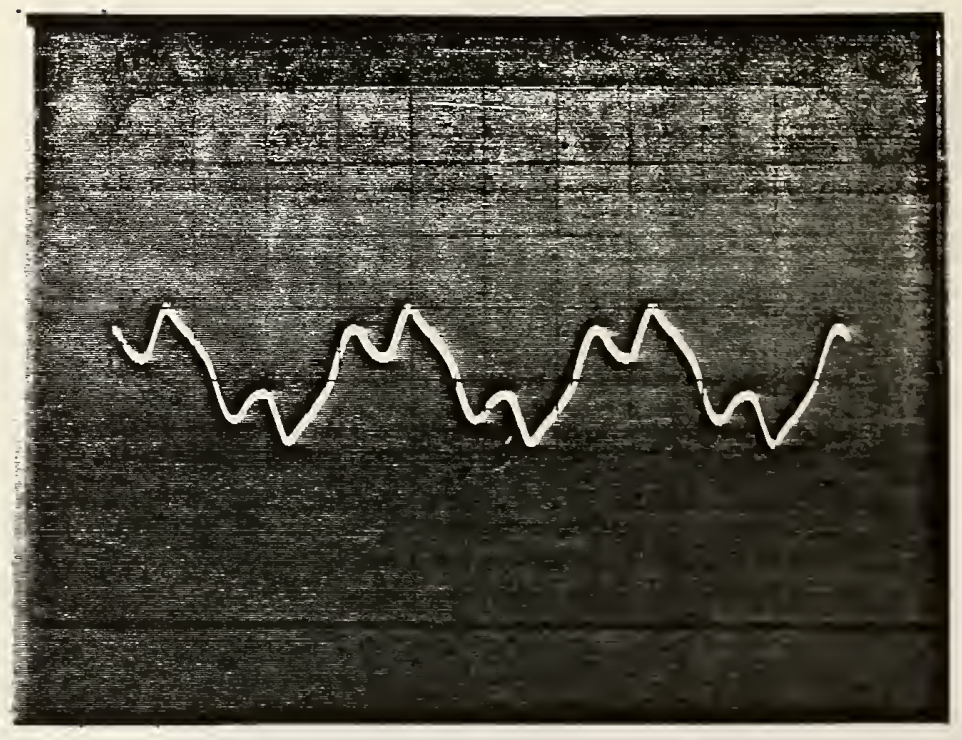

Figure 12a. Oscilloscope display of laboratory ambient magnetic field waveform. Overhead fluorescent lights off. AMFM-1 indication $=27 \mathrm{nT}$ rms. Vertical scale $=50 \mathrm{nT} / \mathrm{div}$. Horizontal scale $=5 \mathrm{~ms} / \mathrm{div}$.

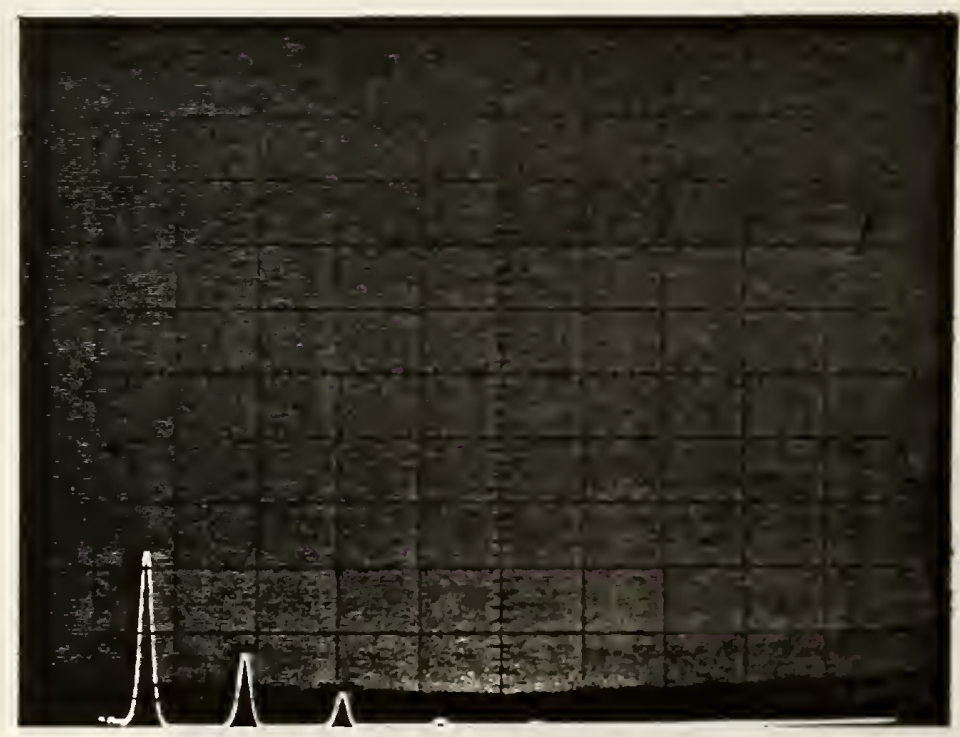

Figure 12b. Absolute scale spectrum analyzer display of figure 12a waveform showing the significant harmonics to be the first, third, fifth, seventh, and ninth, Vertical scale $=10 \mathrm{nT} / \mathrm{div}$. Horizontal scale $=100 \mathrm{~Hz} / \mathrm{div}$. 


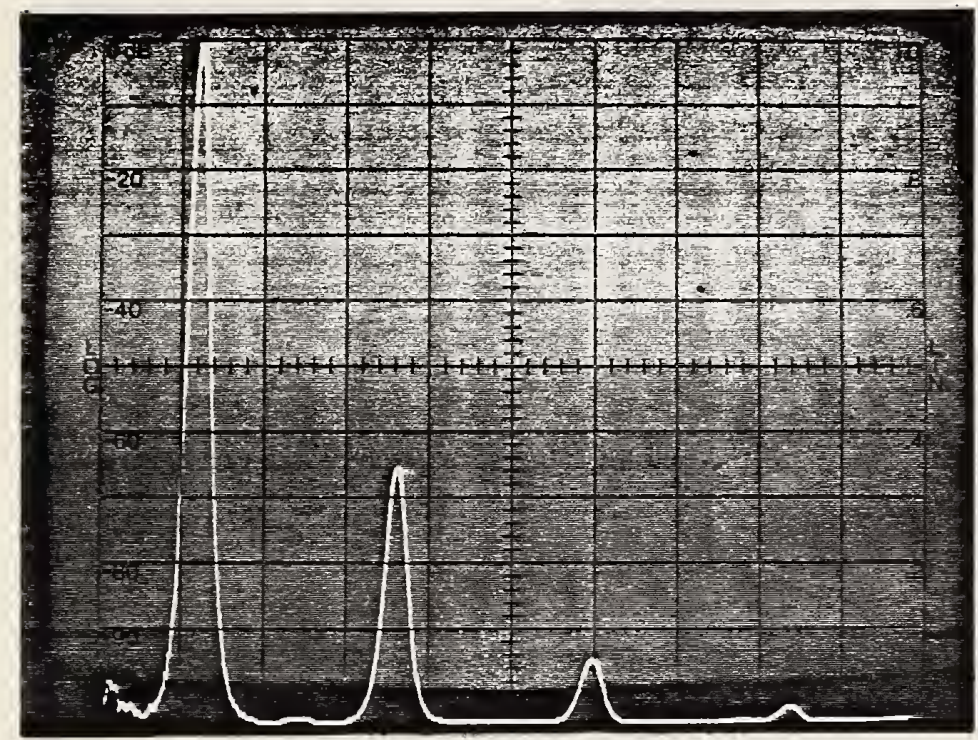

Figure 11c. Normalized spectrum analyzer display for the waveform of figure 11a (laboratory ambient field with overhead fluorescent lights on). Percentage of harmonics relative to the fundamental can be determined from this display after applying correction factors from figure 10. Horizontal scale $=50 \mathrm{~Hz} / \mathrm{div}$.

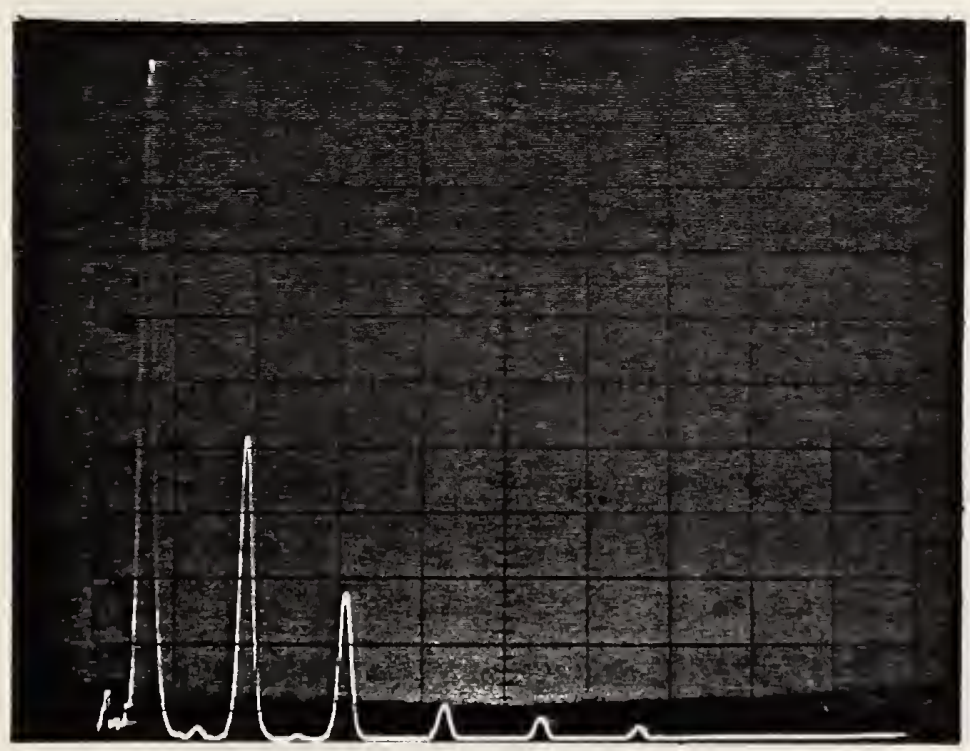

Figure 12c. Normalized spectrum analyzer display for the waveform of figure 12a (laboratory ambient field with overhead flourescent lights of $f$ ). Horizontal scale $=100 \mathrm{~Hz} / \mathrm{div}$. 


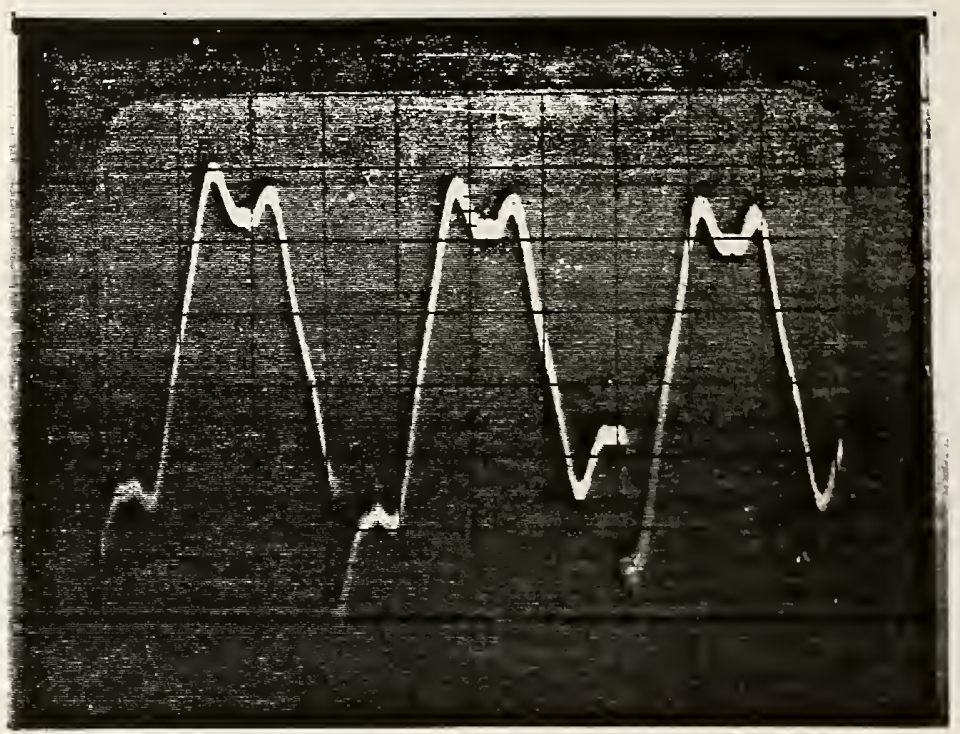

Figure 13a. Oscilloscope display of offlce ambient magnetic field waveform. Computer terminal/disc drive on. AMFM-1 indication $=0.32 \mu \mathrm{T} \mathrm{ms}$. Vertical scale $=0.2 \mu \mathrm{T} / \mathrm{div}$. Horizontal scale $=5 \mathrm{~ms} / \mathrm{div}$.

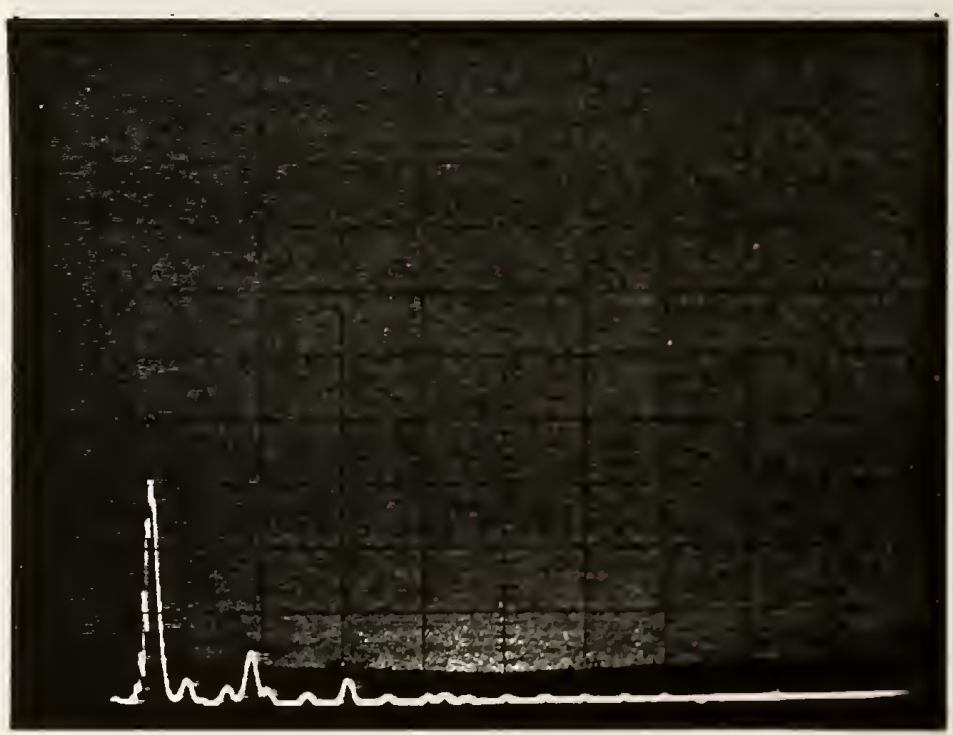

Figure 13b. Absolute scale spectrum analyzer display of figure 13 a waveform showing the major harmonics to be the first, third and fifth, with contributions from many others. Vertical scale $=0.1 \mu \mathrm{T} / \mathrm{d} / \mathrm{V}$. Horizontal scale $=100 \mathrm{~Hz} / \mathrm{div}$. 


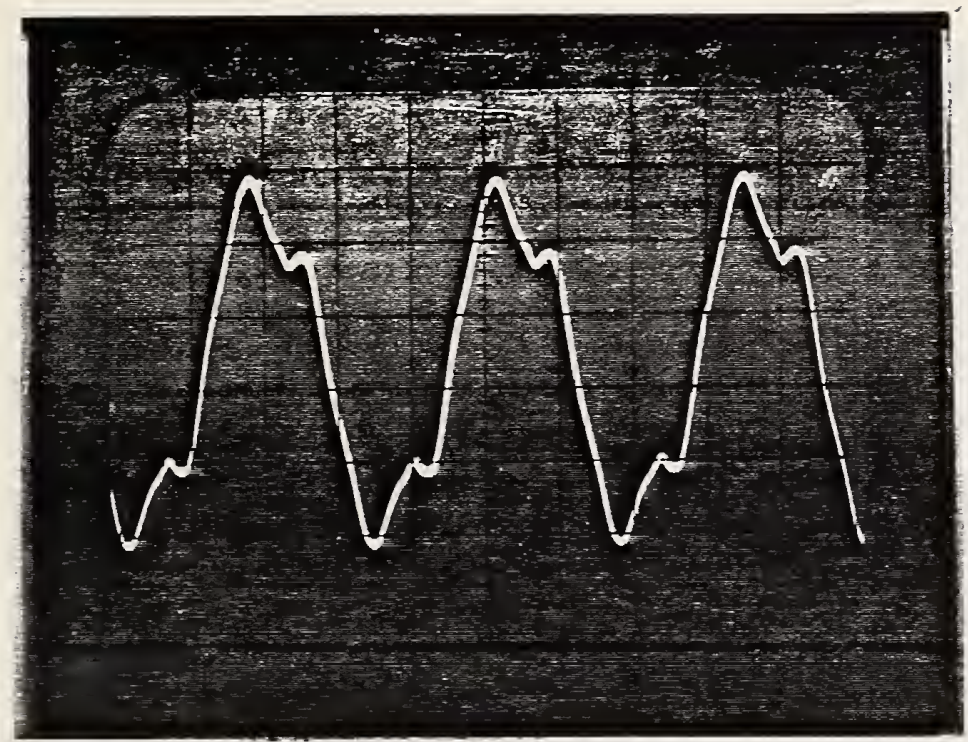

Figure 14a. Oscilloscope display of office ambient magnetic field waveform. Computer terminal/disc drive off. AMFM-1 indication $=0.32 \mu \mathrm{T} r m s$. Vertical scale $=0.2 \mu \mathrm{T} / \mathrm{div}$. Horizontal scale $=5 \mathrm{~ms} / \mathrm{div}$.

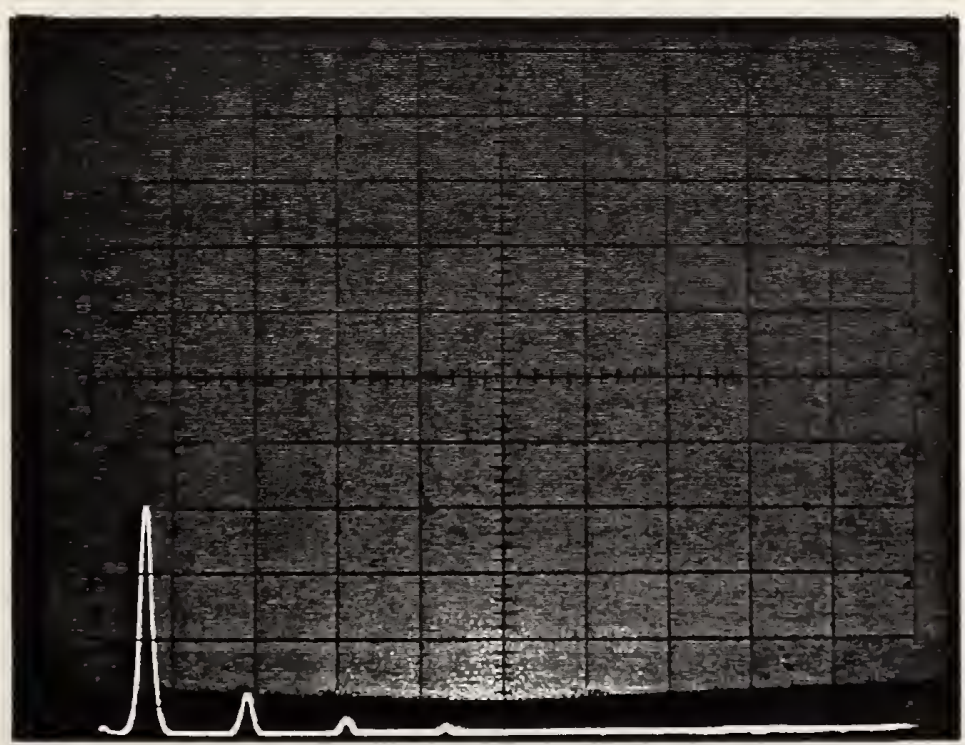

Figure 14b. Absolute scale spectrum analyzer display of figure 14 a waveform showing the significant harmonics to be the first, third, fifth and seventh. Vertical scale $=0.1 \mu \mathrm{T} / \mathrm{div}$. Horizontal scale $=100 \mathrm{~Hz} / \mathrm{div}$. 


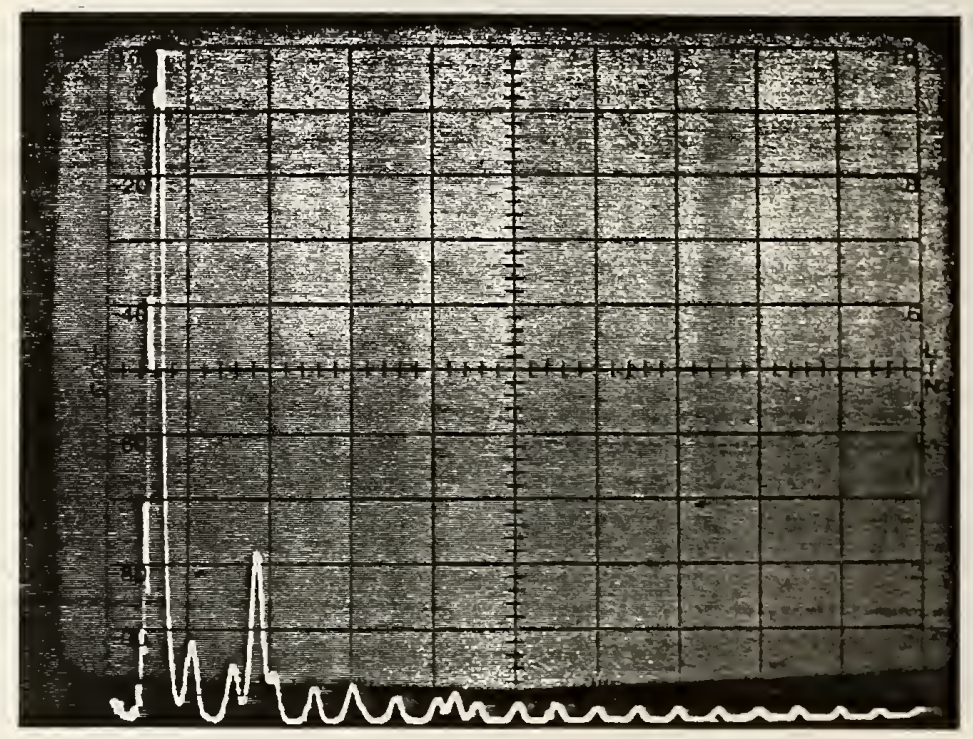

Figure 13 c. Normalized spectrum analyzer display for the waveform of figure $13 a$ (office ambient field with computer terminal/disc drive on). Percentage of harmonics relative to the fundamental can be determined from this display after applying correction factors from figure 10. Horizontal scale $=100 \mathrm{~Hz} / \mathrm{div}$.

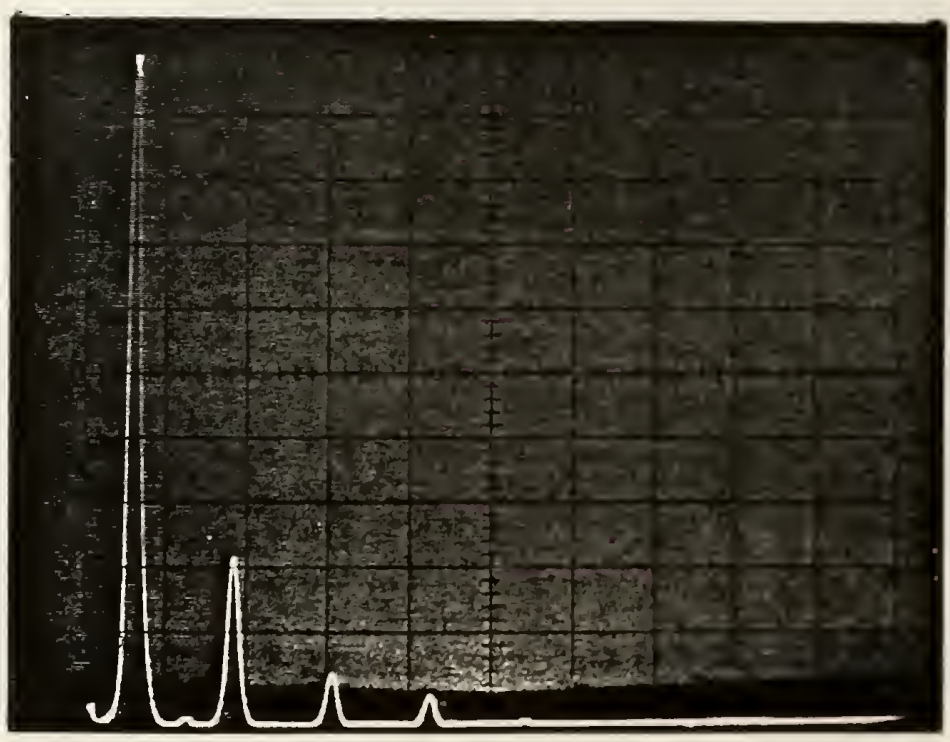

Figure 14c. Normalized spectrum analyzer display for the waveform of figure $14 a$ (office ambient fleld with computer terminal/disc drive of f). Horizontal scale $=100 \mathrm{~Hz} / \mathrm{div}$. 


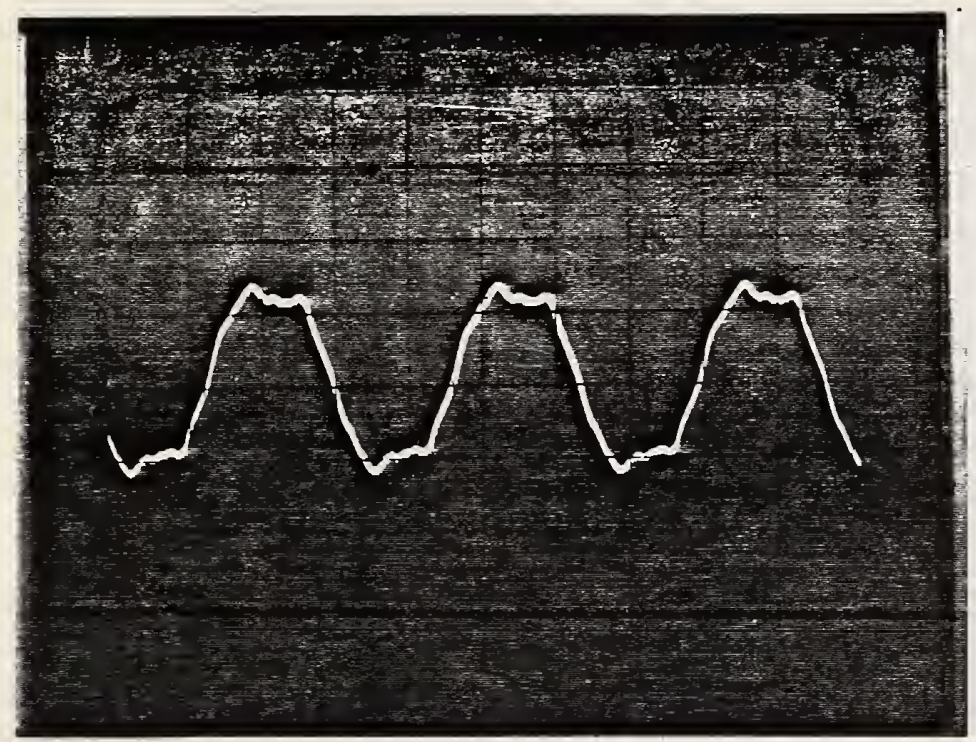

Figure 15a. Oscilloscope display of ambient magnetic field waveform obtained in a home, $30 \mathrm{~cm}$ from, and on same level with a section of unloaded $120 \mathrm{~V}$ ac branch circuit wiring located within the wall. AMFM-1 indication $=10 \mathrm{nT}$ rms. Vertical scale $=10 \mathrm{nT} /$ div. Horizontal scale $=5 \mathrm{~ms} / \mathrm{div}$.

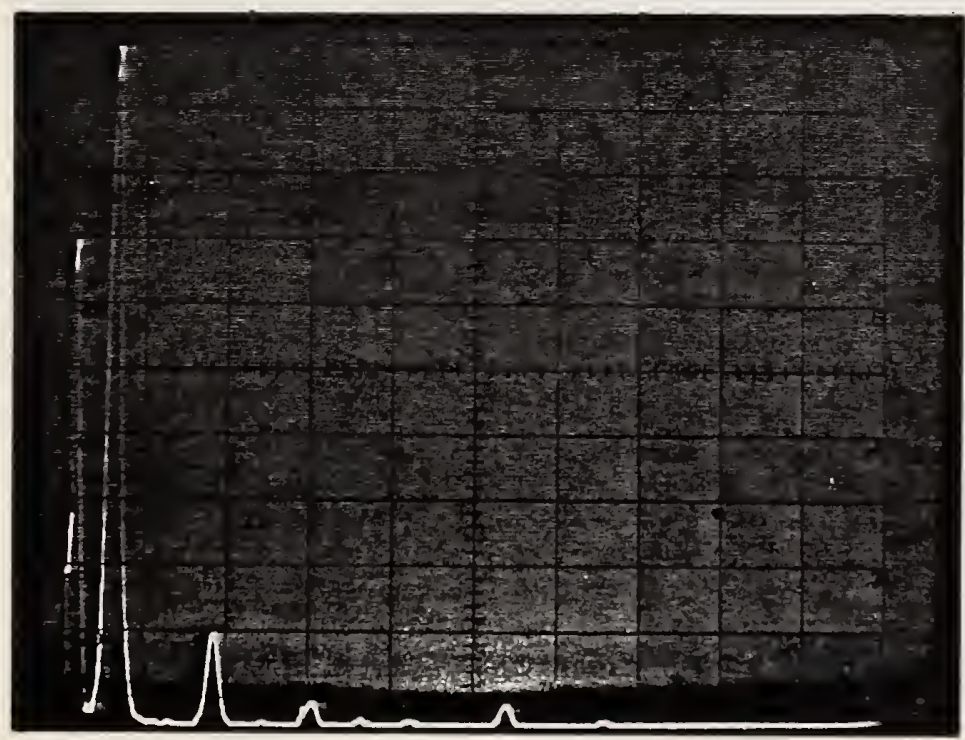

Figure 15b. Absolute scale spectrum analyzer display of figure 15a waveform showing the significant harmonics to be the first, third, fifth and ninth. Since the amplitude of the first harmonic falls at the top of the vertical scale, this figure can also be used as the normalized spectrum analyzer display. Vertical scale $=1.0 \mathrm{nT} / \mathrm{div}$. Horizontal scale $=100 \mathrm{~Hz} / \mathrm{div}$. 


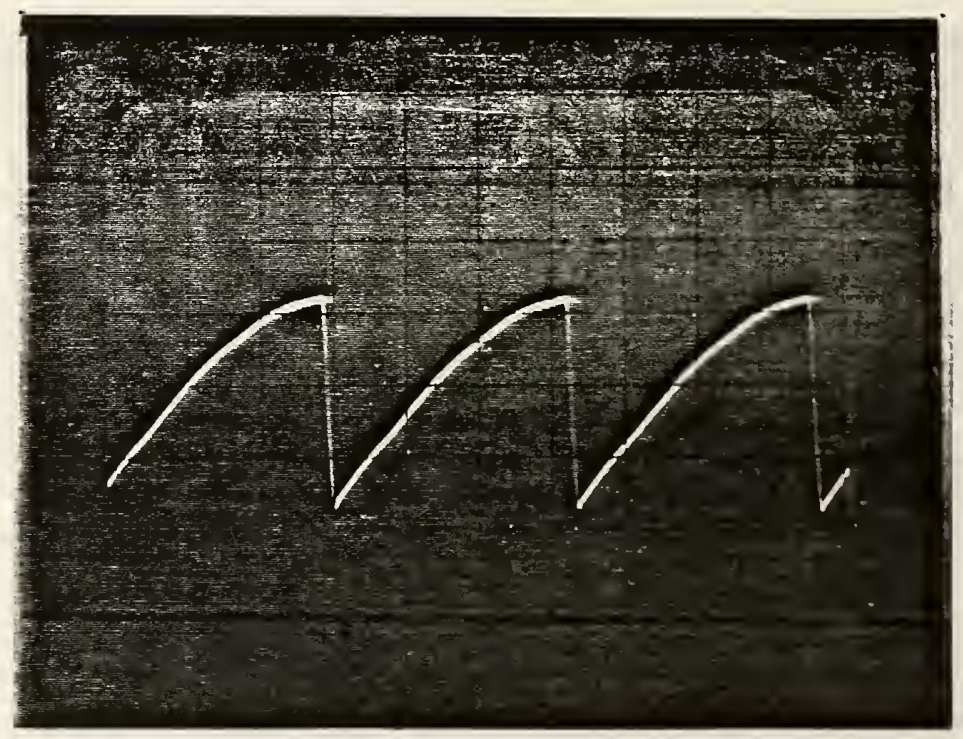

Figure 16a. Oscilloscope display of ambient magnetic field waveform obtained in a home, $60 \mathrm{~cm}$ from the front center of an operating 26-inch screen television set. $A M F M-1$ indication $=0.17 \mu \mathrm{T}$ rms. Vertical scale $=0.2 \mu \mathrm{T} / \mathrm{div}$. Horizontal scale $=5 \mathrm{~ms} / \mathrm{div}$.

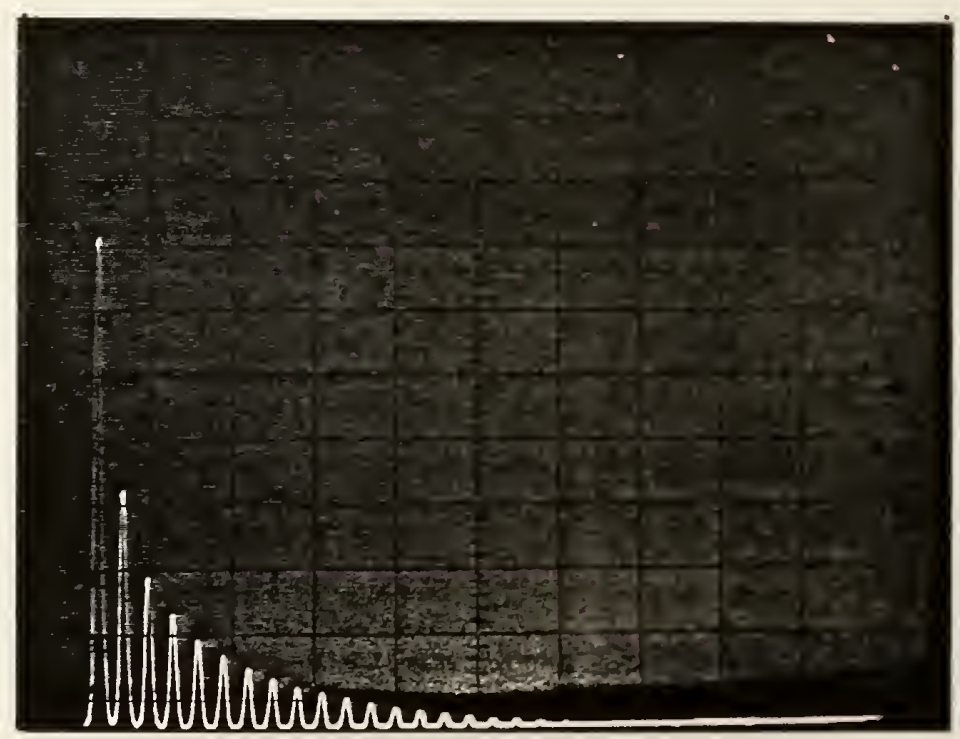

Figure 16b. Absolute scale spectrum analyzer display of f1gure 16a waveform showing a number of significant harmonics whlch decrease in amplitude from the second through the nineteenth. Vertical scale $=0.2 \mu \mathrm{T} / \mathrm{div}$. Horizontal scale $=200 \mathrm{~Hz} / \mathrm{d} I \mathrm{v}$. 


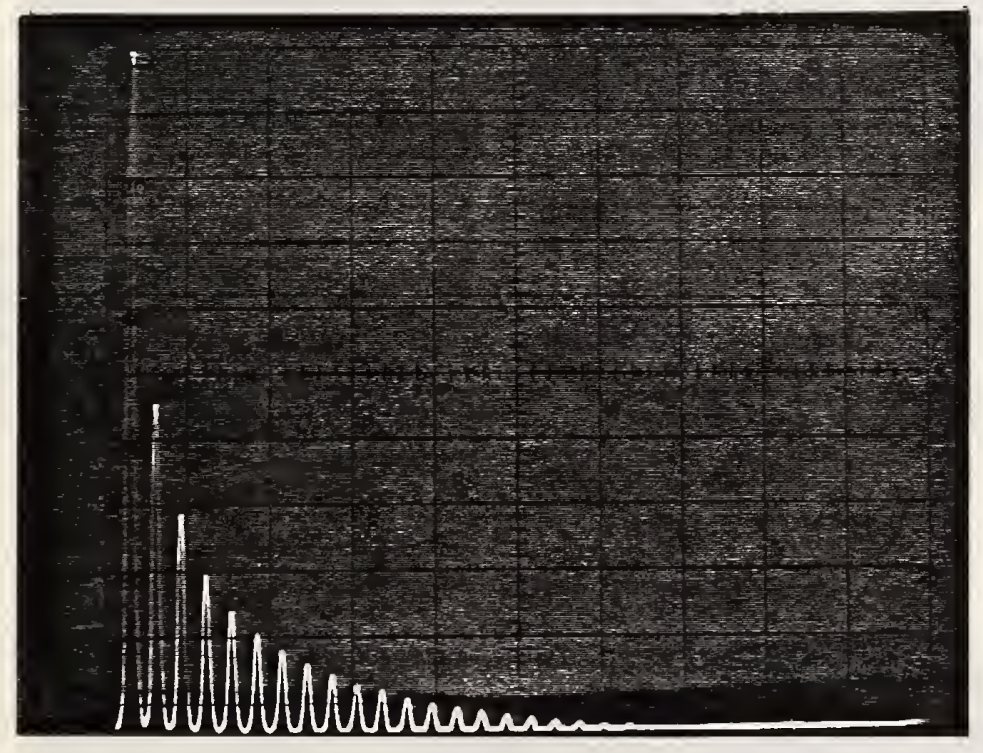

Figure 16c. Normalized spectrum analyzer display for the waveform of figure $16 a$ (home ambient field $60 \mathrm{~cm}$ from front of operating 26-inch TV). Percentage of harmonics relative to the fundamental can be determined from this display after applying correction factors from figure 10. Horizontal scale $=200 \mathrm{~Hz} / \mathrm{div}$. 


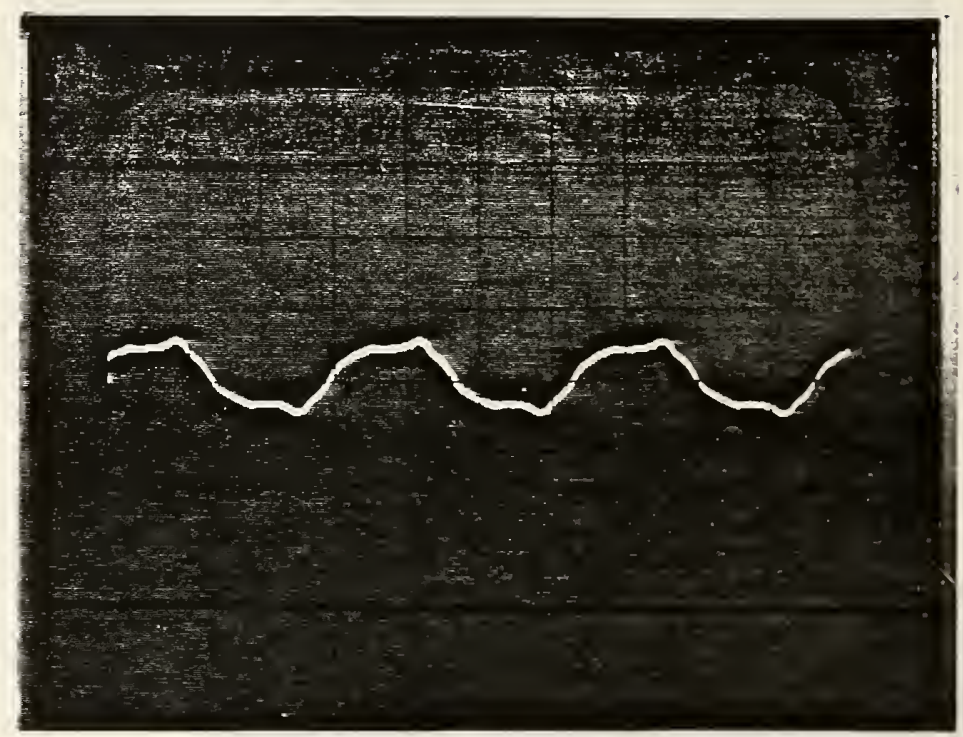

Figure 17a. Oscilloscope display of ambient magnetic field waveform obtalned in a home under the same conditions as figure 16 a except that the TV is turned of $f$. AMFM-1 indication $=8.5 \mathrm{nT}$ rms. Vertical scale $=20 \mathrm{nT} / \mathrm{div}$. Horizontal scale $=5 \mathrm{~ms} / \mathrm{div}$.

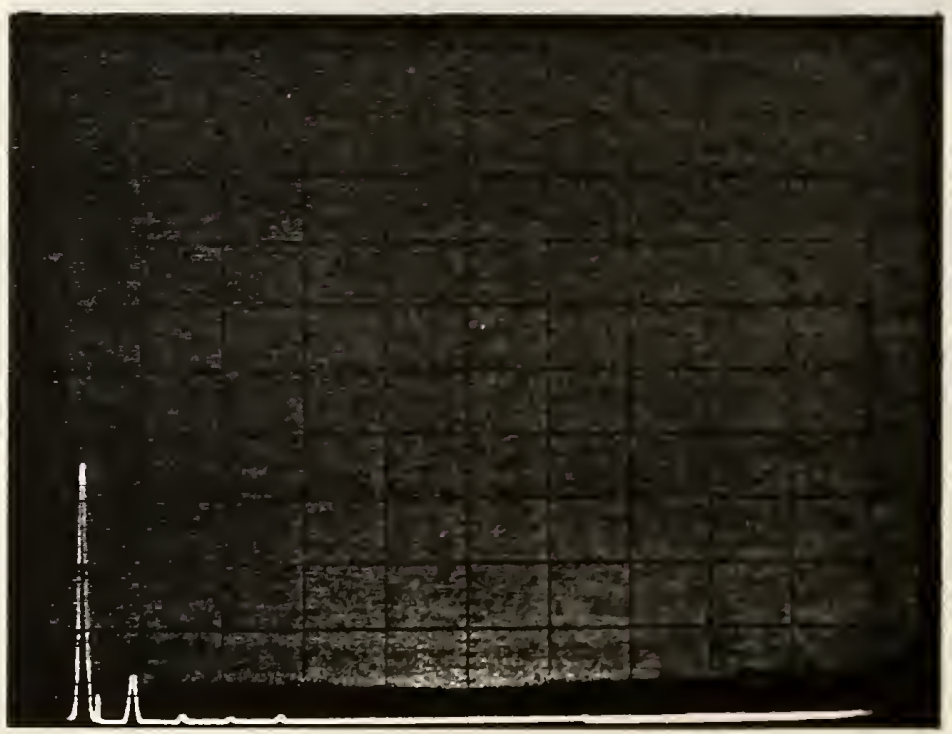

Figure 17b. Absolute scale spectrum analyzer display of figure 17 a waveform showing the significant harmonics to be the first and third. Vertical scale $=2.0 \mathrm{nT} / \mathrm{div}$. Horizontal scale $=200 \mathrm{~Hz} / \mathrm{dlv}$. 


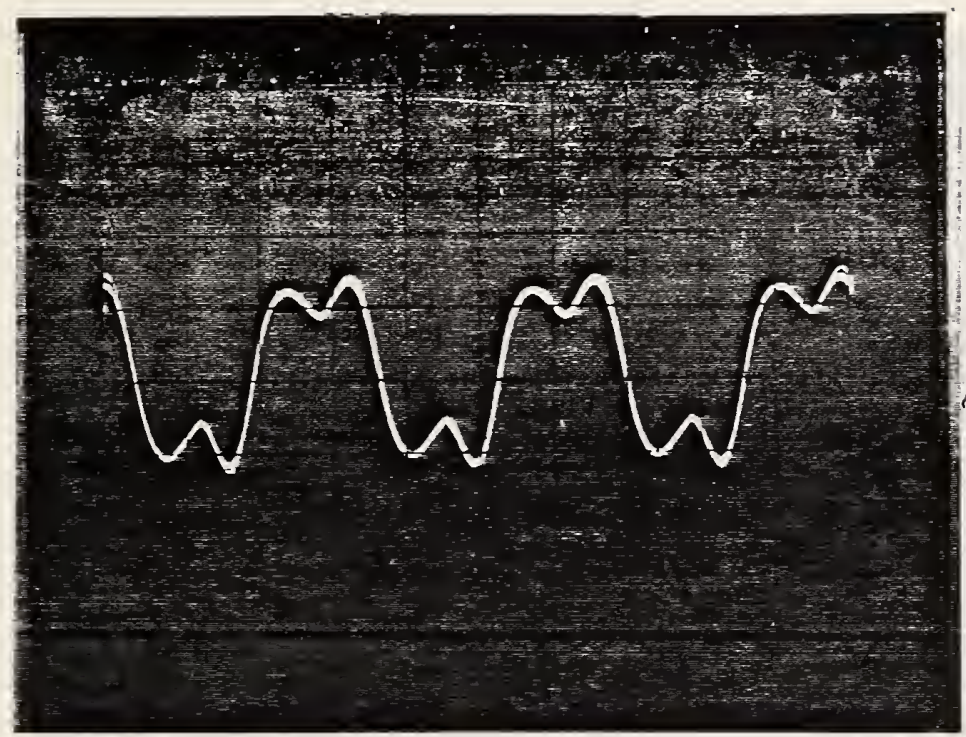

Figure 18a. Oscilloscope display of ambient magnetic field waveform obtained in a home $15 \mathrm{~cm}$ from the front of an operating microwave oven. AMFM-1 indication $=4.7 \mu \mathrm{T}$ rms. Vertical scale $=5 \mu \mathrm{T} /$ div. Horizontal scale $=5 \mathrm{~ms} / \mathrm{div}$.

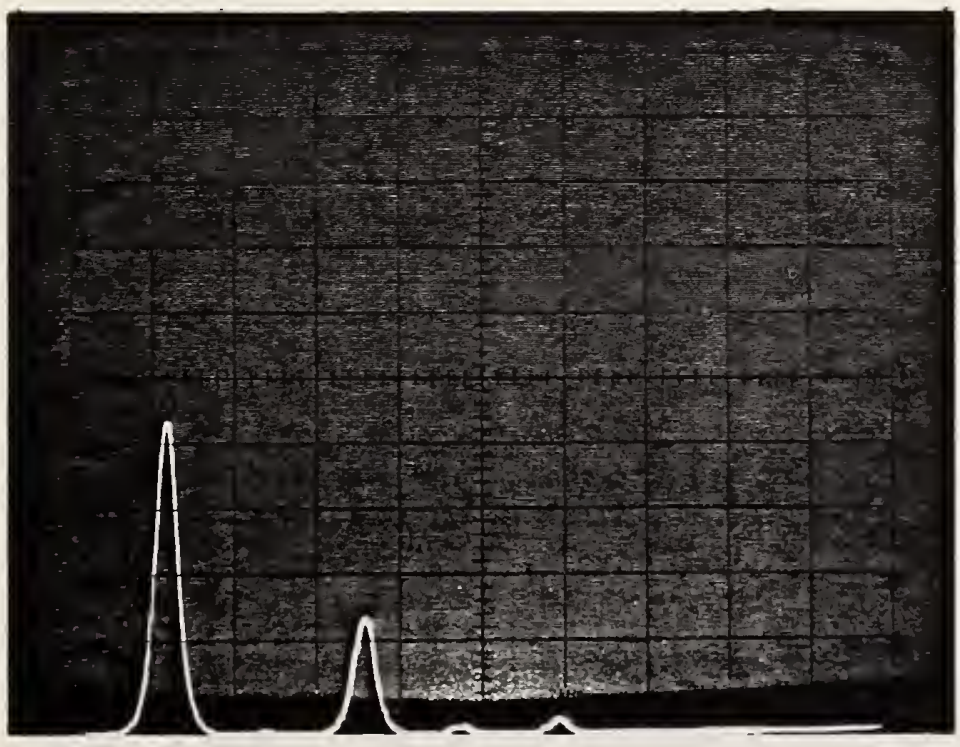

Figure 18b. Absolute scale spectrum analyzer display of figure 18a waveform showing the significant harmonics to be the first, third, fourth and fifth. Vertical scale $=1.0 \mu \mathrm{T} / \mathrm{div}$. Horizontal scale $=50 \mathrm{~Hz} / \mathrm{div}$. 


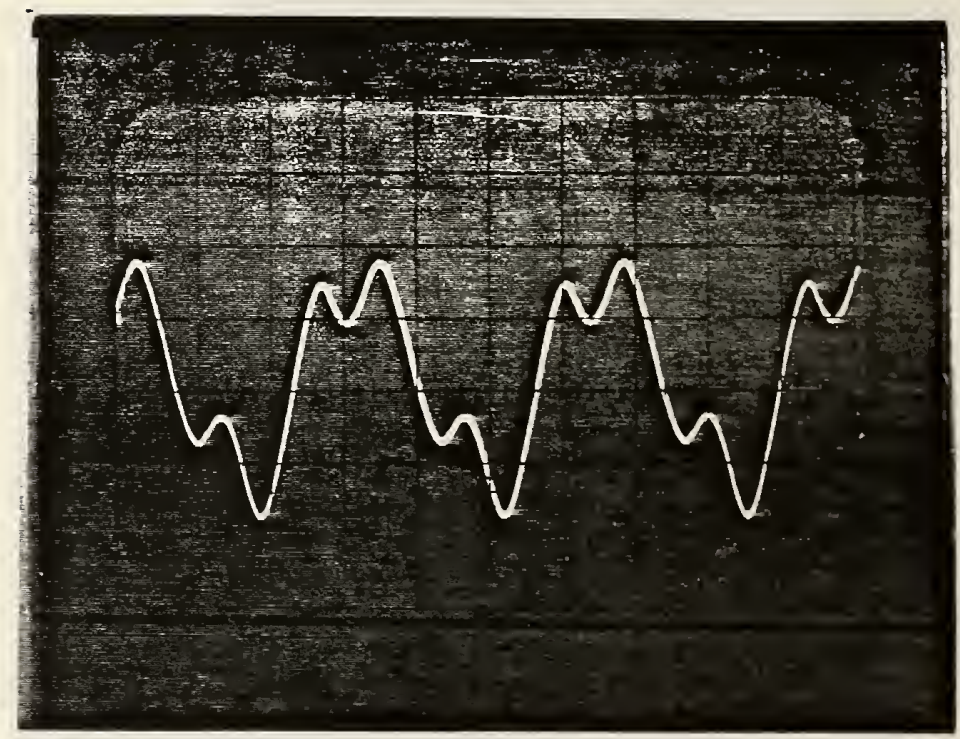

Figure 19a. Oscilloscope display of ambient magnetic fleld waveform obtained in a home under the same conditions as figure 18 a except that the microwave oven is of $\mathrm{f}$. AMFM-1 indication $-52 \mathrm{nT}$ rms. Vertical scale $=50 \mathrm{nT} / \mathrm{div}$. Horizontal scale $=5 \mathrm{~ms} / \mathrm{div}$.

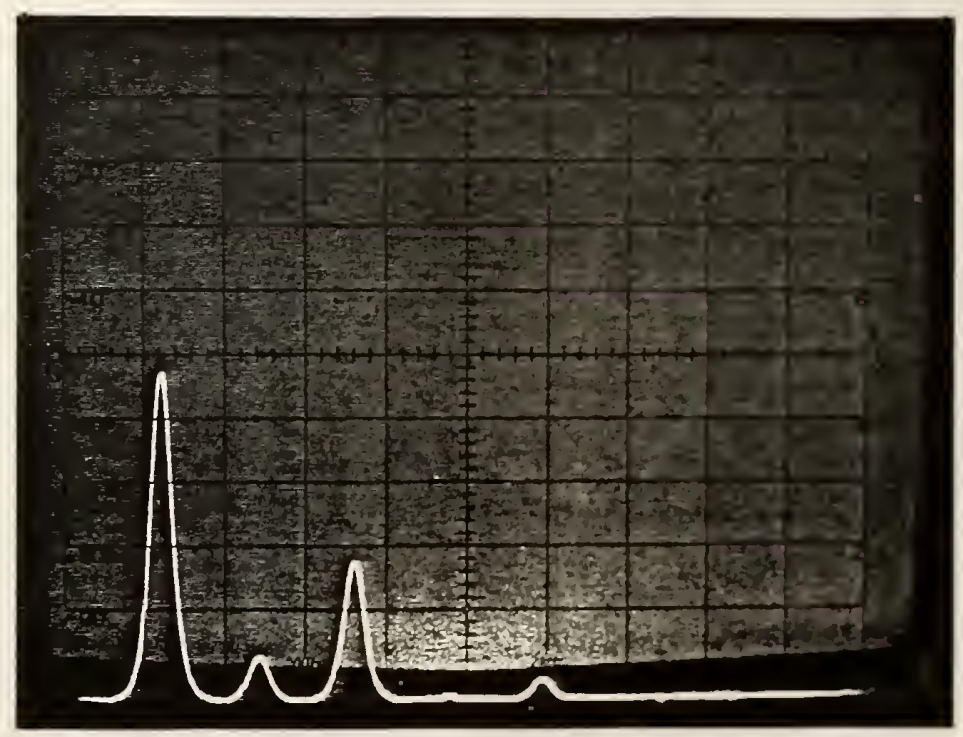

Figure 19b. Absolute scale spectrum analyzer display of flgure 19a waveform showing the slgniflcant harmonics to be the flrst, second, third and fifth. Vertical scale $=10 \mathrm{nT} / \mathrm{div}$. Horizontal scale $=50 \mathrm{~Hz} / \mathrm{div}$. 


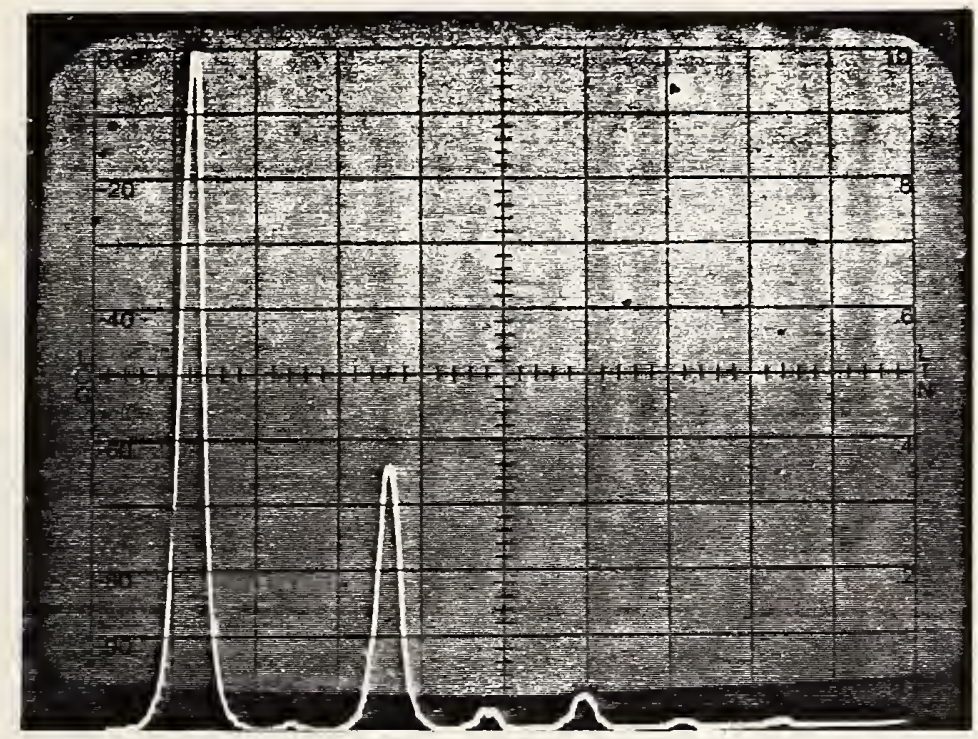

Figure 18c. Normalized spectrum analyzer display for the waveform of figure 18a (home ambient field in front of operating microwave oven). Percentage of harmonics relative to the fundamental can be determined from this display after applying correction factors from figure 10. Horizontal scale $=50 \mathrm{~Hz} / \mathrm{div}$.

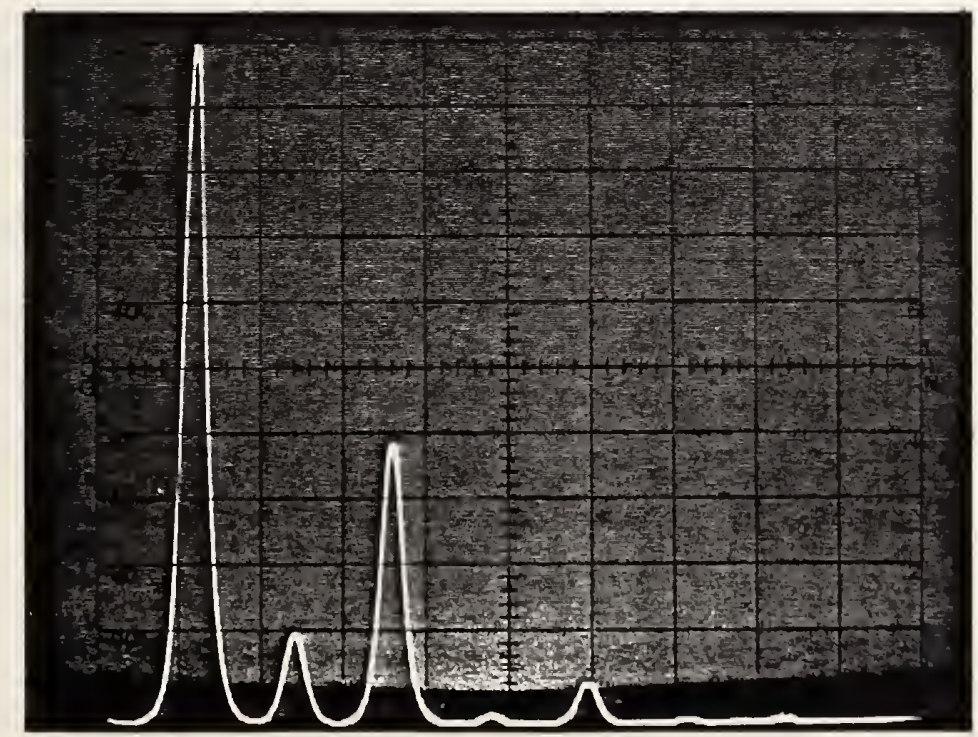

Figure 19c. Normalized spectrum analyzer display for the waveform of figure 19a (home ambient field in front of non-operating microwave oven). Horizontal scale $=50 \mathrm{~Hz} / \mathrm{div}$. 


\section{ACKNOWLEDGMENTS}

The author is pleased to acknowledge the assistance of Arnold Perrey in the layout and construction of the fieldmeter, the assistance of Barbara Frey and Roberta Cummings during preparation of this manuscript, and the useful conversations with Martin Misakian, Owen Laug, Robert Hebner and

Oskars Petersons. The support of the Department of Energy is also gratefully acknowledged. 


\section{REFERENCES}

[1] N. Wertheimer and E. Leeper, "Electrical Wiring Configurations and Childhood Cancer," American Journal of Epidemiology, Vol. 109, No. 3, (1979), pp. 273-284.

[2] "Extremely Weak Magnetic Fields Affect Behavior," Microwave News, Vol. 4, No. 9, (1984), pp. 1-2.

[3] G. Theriault, "Critical Review of Epidemiological Studies on the Relationship Between Various Electromagnetic Parameters and the Incidence of Cancer," School of Occupational Health, McGill University, Montreal, Quebec, Canada, May 10, 1984, 27 pages.

[4] P. Beiersdorfer and E. J. Clothiaux, "High-Frequency Magnetic Measurement Using Small Inductive Probes," American Journal of Physics, Vol. 51, No. 11 (1983), pp. 1031-1036.

[5] J. R. Reitz and F. J. Milford, "Foundations of Electromagnetic Theory," Reading MA: Addison-Wesley; 1960, p. 156.

[6] M. A. Plonus, "Applied Electro-Magnetics," New York: McGraw-Hill; 1978, p. 225.

[7] J. A. Stratton, "Electromagnetic Theory," New York: McGraw-Hill, 1941. p. 233.

[8] E. R. Williams and P. T. Olsen, "New Measurement of The Proton Gyromagnetic Ratio and $A$ Derived Value of the Fine Structure Constant Accurate to A Part in $10^{7}$," Physical Review Letters, vol. 42, No. 24 , (1979), pp. 1575-1579.

[9] Forest K. Harris, "A Nonmagnetic laboratory for the National Bureau of Standards," IEEE Spectrum, Nov. 1966, p. 85.

[10] S. Ramo and J. R. Whinnery, "Fields and Waves in Modern Radio," New York; John Wiley and Sons; 1944, p. $141 \mathrm{ff}$.

[11] E. R. Peck, "Electricity and Magnetism," New York; McGraw-Hill; 1953, p. 209 . 


\section{APPENDIX}

\section{CALCULATION OF COMBINED UNCERTAINTY DUE TO POSSIBLE PROBE MISALIGNMENT WITHIN HELMHOLTZ COILS AND TO FIELD VARIATION OVER AREA OF PROBE}

The uncertainties due to the possible misalignment of the AMFM-1 magnetic field probe from its intended central position within the Helmholtz coil pair and to the variation in magnetic field, $B_{h}$, from its central value over the area of the probe can be combined and calculated. For simplicity, this is done in two steps, first determining the variation in $B_{\text {h }}$ that occurs within the Helmholtz colls over an area somewhat larger than the probe to allow for probe misalignment from its intended center position while its plane remains perpendicular to that of the coll axis, and then adding to this the error which can occur if the plane of the probe is not perpendicular to the coll axis. The same procedure also applies to possible misalignment of the magnetometer probe which is used in determining the dc Helmholtz coll factor, $\mathrm{K}_{\mathrm{H}}$ •

Referring to the diagram of figure 20, the field parallel to the

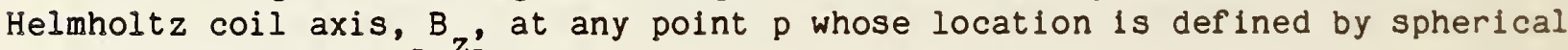
coordinates $r$ and $\theta[1, j]$ is

$$
B_{z}(r, \theta)=\frac{\mu_{0} N h b^{2}}{2\left(b^{2}+d^{2}\right)^{1.5}}\left[2+A_{2}\left[P_{2}(\cos \theta)\right] r^{2}+A_{4}\left[P_{4}(\cos \theta] r^{4}+\ldots\right]\right.
$$

where $A_{2}=\frac{15 d^{2}-3\left(b^{2}+d^{2}\right)}{\left(b^{2}+d^{2}\right)^{2}}$

$$
A_{4}=\frac{15\left(b^{2}+d^{2}\right)^{2}-210 d^{2}\left(b^{2}+d^{2}\right)+315 d^{4}}{4\left(b^{2}+d^{2}\right)^{4}}
$$

and $b$ is the coil radius, $d$ is one-half the coll spacing, $\mu_{0}$ is the permeability of air (vacuum), $N$ the number of turns on each coll, I the ac current through the colls and $P(\cos \theta)$ are Legendre polynomials of order $\mathrm{m}$. For Helmholtz coils where, $2 \mathrm{~d}=\mathrm{b}^{\mathrm{m}}$, the term involving $\mathrm{A}_{2}$ vanishes, the value of $\mathrm{A}_{4}$ becomes approximately $1 / 7(\mathrm{~d})^{4}$ and the fleld is fairly uniform over a volume surrounding the center. The dimensional uncertainty of $b$ and $d$ due to the finite size of the wire bundle comprising $\mathrm{N}$ on each coll was accounted for during the determination of the Helmholtz coll factor, $k_{h}$, and does not add further uncertainty.

Equation (B-1) was evaluated by computer over a volume defined by a cylinder with axial symmetry, centered within the colls, $6 \mathrm{~cm}$ thlck along the $z$ axis and $16 \mathrm{~cm}$ in diameter in the $x, y$ plane. Since the AMFM-1 probe outer dimensions are approximately $2 \mathrm{~cm}$ thick by $10 \mathrm{~cm}$ in outside diameter, the probe could be positioned of center by $3 \mathrm{~cm}$ in any direction and still remain within the above defined cylinder. The values of (1) $\theta=90^{\circ}$ with $r=0.08$ meter and $(2) \theta=\cot ^{-1}(z / x)$ with $x$ equal to plus or migus 0.08 meter and $z$ equal to plus or minus 0.03 meter (and hence $r=\left[(0.08)^{2}+(0.03)^{2}\right]^{1 / 2}$ derine the edges of said cylinder. Computer evaluation provided a maximum deviation in $B_{2}$ (equivalent to $B_{h}$ ) of $\pm 0.15 \%$ from nominal at the outer edge of the defined cylinder. The worst case occurs when the probe is shifted only in the $x, y$ plane away from center, 1.e., $\theta=90^{\circ}$ and $r=0.08$ meter. However, if the 


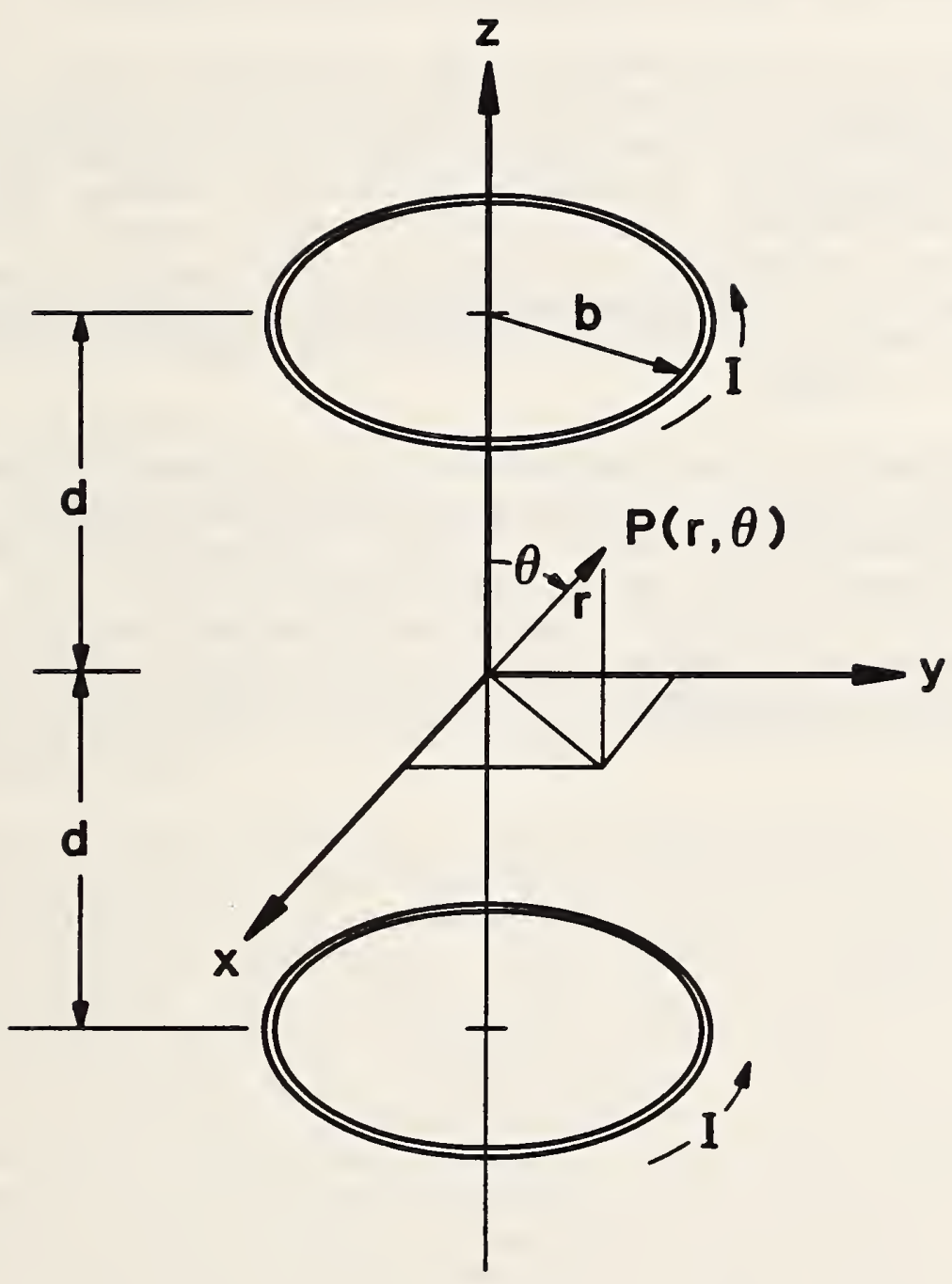

Figure 20. Configuration of Helmholtz coil pair for generating a magnetic field in the $Z$ direction, together with the coordinate system used in the discussion of field variation at points away from center. 
outer edge of the probe were $8 \mathrm{~cm}$ from the Helmholtz coll central axis, the center of the probe would be approximately $3 \mathrm{~cm}$ from the axis and the error at this point $\left(\theta=90^{\circ}\right.$ and $r=0.03$ meter) is only $0.003 \%$. Since the probe averages the magnetic field over its area, an uncertainty specification of $\pm 0.1 \% 18$ more than adequate for this portion of the position error.

In addition to being centered along the Helmholtz coll axis, the plane of the probe should also be perpendicular to the axis. Variation of the probe plane from perpendicular to the axis produces a percentage error which can be determined by $(1-\cos \phi) \times 100$ where $\phi$ is the angle between the plane of the probe and a plane perpendicular to the coll axis. Assuming a maximum possible misadjustment of 3 degrees, the uncertainty resulting is $\left(1-\cos 3^{\circ}\right) \times 100$ or 0.14\%. Adding this to the uncertainties due to possible position error $(0.1 \%+0.14 \%)$ results in a total possible uncertainty due to AMFM-1 probe misalignment of $< \pm 0.24 \%$.

The magnetometer probe sensing area is approximately $6 \mathrm{~cm}$ long and $2 \mathrm{~cm}$ square, hence the outer limits of its reasonable misplacement should also flt within the cylinder defined above. In fact, because of its smaller area normal to the Helmholtz coil axis, displacements greater than $3 \mathrm{~cm}$ from the axis should easily be noticed. Angular misadjustment would also be more noticeable because of its shape, hence the three degree maximum assumed for the AMFM-1 probe is applicable. 
4. TITLE AND SUBTITLE

NBS Ambient Magnetic Field Meter for Measurement and Analysis of Low-Level Power Frequency Magnetic Fields in Air

\section{AUTHOR(S)}

P. M. Fulcomer

6. PERFORMING ORGANIZATION (If joint or other than NBS, see instructions)

7. ContracU Grant No.

MATIONAL BUREAU OF STANDARDS

DEPARTMENT OF COMMERCE

WASHINGTON, D.C. 20234

8. Type of Report \& Period Covered

1. SPONSORING ORGANIZATION NAME AND COMPLETE ADDRESS (Street, City, Stote, ZIP)

Department of Energy

Division of Electric Energy Systems

1000 Independence Avenue, S. W.

Washington, DC 20585

1. SUPPLEMENTARY NOTES

Document describes a computer program; SF-185, FIPS Software Summary, is attached.

1. ABSTRACT (A 200-word or less factual summary of most significant information. If document includes a significant bibliography or literature survey, mention it here)

This report describes a portable, battery-powered magnetic fieldmeter which has been developed to provide improved accuracy in the measurement and analysis of low-level and ambient power-frequency magnetic fields. Accurate measurement of such fields is becoming increasingly important as public concern grows over the possibility that exposure to such fields may produce effects on human health. Included in the report are a description of the instrumentation, a circuit analysis, a discussion of the calibration procedures together with an uncertainty analysis, and some sample measurement results. The instrumentation enables measurement of power-frequency magnetic field in air with an overall uncertainty of less than one percent over a range from 50 nanotesla ( 500 microgauss) to $200 \mathrm{microtesla} \mathrm{(2} \mathrm{gauss)} \mathrm{and} \mathrm{an} \mathrm{overall}$ uncertainty of less than two percent down to 2 nanotesla (20 microgauss). It also enables the percentage of each harmonic present in the field to be determined to an uncertainty of less than three percent.

12. KEY WORDS (Six to twelve entries; alphabetical order; capitalize only proper names; and separate key words by semicolons) ambient magnetic field; - calibration: calibration uncertainty; flux density: low-levèl magnetic fiêld; mànetic fieldmeter; magnetic fièld "strènth; magnetic flux density; magnetic induction; measure; meter; power frequency magnetic field 13. AVAILABILITY

Unlimited

$\square$ For Official Distribution. Do Not Release to NTIS

$\square$ Order From Superintendent of Documents, U.S. Government Printing Office, Washington, D.C. 20402.

XX Order From National Technical Information Service (NTIS), Springfield, VA. 2216I

14. NO. OF PRINTED PAGES

58

15. Price 


